\title{
The requirement of integrins for breast epithelial proliferation
}

\section{DOI:}

10.1016/j.ejcb.2017.03.005

\section{Document Version}

Accepted author manuscript

Link to publication record in Manchester Research Explorer

\section{Citation for published version (APA):}

Moreno Layseca, P., Ucar, A., Sun, H., Wood, A., Olabi, S., Gilmore, A., Brennan, K., \& Streuli, C. (2017). The requirement of integrins for breast epithelial proliferation. European journal of cell biology.

https://doi.org/10.1016/j.ejcb.2017.03.005

\section{Published in:}

European journal of cell biology

\section{Citing this paper}

Please note that where the full-text provided on Manchester Research Explorer is the Author Accepted Manuscript or Proof version this may differ from the final Published version. If citing, it is advised that you check and use the publisher's definitive version.

\section{General rights}

Copyright and moral rights for the publications made accessible in the Research Explorer are retained by the authors and/or other copyright owners and it is a condition of accessing publications that users recognise and abide by the legal requirements associated with these rights.

\section{Takedown policy}

If you believe that this document breaches copyright please refer to the University of Manchester's Takedown Procedures [http://man.ac.uk/04Y6Bo] or contact uml.scholarlycommunications@manchester.ac.uk providing relevant details, so we can investigate your claim.

\section{OPEN ACCESS}




\section{Abstract}

Epithelial cells forming mammary gland ducts and alveoli require adhesion to the extracellular matrix for their function. Mammary epithelial cells need $\beta 1$-integrins for normal cell cycle regulation. However, the role of $\beta 1$-integrins in tumorigenesis has not been fully resolved. $\beta 1$-integrin is necessary for tumour formation in transgenic mice expressing the Polyomavirus Middle $\mathrm{T}$ antigen, but it is dispensable in those overexpressing ErbB2. This suggests that some oncogenes can manage without $\beta 1$-integrin to proliferate and form tumours, while others still require it. Here we have developed a model to test whether expression of an oncogene can surpass the need for $\beta 1$-integrin to drive proliferation. We coexpressed the ErbB2 or Akt oncogenes with shRNA to target $\beta 1$-integrin in mammary epithelial cells, and found that they show a differential dependence on $\beta 1$-integrin for cell division. Moreover, we identified a key proliferative role of the Rac1-Pak axis downstream of $\beta 1$-integrin signalling. Our data suggest that, in mammary epithelial cells, oncogenes with the ability to signal to Pak surpass the requirement of integrins for malignant transformation. This highlights the importance of using the correct combination therapy for breast cancer, depending on the oncogenes expressed in the tumour.

Keywords: Beta1-integrin, mammary epithelial cells, proliferation, oncogenes

Abbreviations: MECs - Mammary Epithelial Cells 


\section{Introduction}

Integrins are adhesion receptors that control several functions in mammary epithelium, such as differentiation, polarity and proliferation (Glukhova and Streuli 2013). Of the integrin subunits expressed by mammary epithelial cells (MECs), the $\beta 1$-subunit plays a key role during G1/S transition ( $\mathrm{Li}$, et al. 2005; Jeanes, et al. 2012). Previous studies on the role of ß1-integrin in MEC proliferation have used alveolar tissue or cells isolated from pregnant mice. However, integrin-dependent pathways controlling proliferation in cells from virgin mice (ductal MECs) remain understudied. Since increased cell cycle is one of the hallmarks of cancer and most breast tumours are not pregnancy-related, it is important to understand the signalling pathways regulating proliferation in ductal MECs.

Integrin expression is altered in breast cancer. During early stages, the $\beta 1$-integrin subunit is downregulated in human breast tumours (Zutter, Mazoujian, and Santoro 1990; Zutter, Krigman, and Santoro 1993). Conversely in invasive breast cancers, $\beta 1$-integrin is often overexpressed, and this correlates with a poor prognosis (dos Santos, et al. 2012). Studies investigating whether $\beta 1$-integrins are required for tumorigenesis have shown contradictory results. For example, $\beta 1$-integrin is required for tumour formation in transgenic mice carrying the Polyomavirus middle T promoter (White, et al. 2004). However, in a $\beta 1$-integrin-null mouse strain in which activated ErbB2 is expressed, the lack of $\beta 1$-integrin only delayed the formation of tumours, suggesting that $\beta 1$-integrin is not necessary for cancer initiation (Huck, et al. 2010). Additionally, the metastatic properties of the tumours were decreased in $\beta 1$ integrin-null mice. $\beta 1$-integrin may therefore be important during metastasis, but not during initial tumour formation. Furthermore, some oncogenes may overcome the need for $\beta 1$ integrin to progress in the cell cycle during tumorigenesis, but it is not known which oncogenes can do this.

The fact that some oncogenes such as ErbB2 easily overcome the need for this integrin, while others (such as Polyomavirus Middle $\mathrm{T}$ antigen) require it, calls for a model system 
where the mechanistic details of these interactions can be elucidated. In this study, we have established a robust method to study both $\beta 1$-integrin-dependent and independent (oncogene-driven) proliferative pathways in MECs.

In normal mammary epithelium, ErbB2 regulates ductal elongation and branching during puberty (Hynes and Lane 2005). ErbB2 has no known ligand, requires to be transactivated by another ErbB receptor, and is overexpressed in $20 \%$ of breast cancers (Slamon 1987). This leads to the receptor no longer requiring ligand (when bound to another ErbB receptor) or receptor dimerization for activation (Penuel, Akita, and Sliwkowski 2002). Although $\alpha 6 \beta 4$ integrin contributes to ErbB2-induced tumorigenesis, $\beta 1$-integrin seems to be dispensable for tumorigenesis in the mammary epithelium (Guo, et al. 2006; Huck, et al. 2010).

The serine/threonine kinase Akt is the central effector of PI3K signalling (Viglietto, et al. 2002; Zhang, et al. 2011). In breast cancer, Akt is often activated due to upstream signal deregulation. Moreover, there can be somatic mutations in Akt, for example a lysine substitution at E17 occurs in 6\% of breast tumours (Carpten, et al. 2007; Kim, et al. 2008). Other activating mutations in the $\mathrm{PH}$ domain of Akt (L52R, Q79K) and one in the kinase domain $(\mathrm{D} 323 \mathrm{H})$ are present in $4 \%$ of breast cancers (Parikh, et al. 2012).

Here, we have studied the signalling pathways that are disrupted when $\beta 1$-integrin is depleted in ductal MECs isolated from nulliparous mice (Kittrell, Oborn, and Medina 1992). We found that ductal MECs require Rac1 and Pak signalling for normal proliferation. Furthermore, we used this model to test the dependence of oncogenic ErbB2 and Akt on $\beta 1$ integrin to drive proliferation. We show that ErbB2, but not Akt, can surpass the need for $\beta 1$ integrin to promote MEC proliferation. Our data also suggest that Akt is not required for ErbB2-mediated transformation, either in the presence or absence of $\beta 1$-integrins. Thus oncogenes with the ability to signal to Pak are able to override the integrin requirement for MEC proliferation. With this work, we have established a simple model to study the dependence of oncogenes on $\beta 1$-integrin to drive proliferation in ductal MECs. 


\section{Materials and methods}

DNA constructs: The shRNAmiR sequence for mouse $\beta 1$-integrin and the high cycling L61Rac1 were cloned in the lentivector pIV-Venus (Tronolab, EPFL) and have been previously described (Jeanes, et al. 2012). The plasmid pCDNA3-GFP- $\beta 1$-integrin was a kind gift from Prof Bernard Wehrle-Haller (University of Geneva). To construct the human $\beta 1$-integrin rescue vector, four silent point mutations were introduced in pCDNA3- $\beta 1$-integrin using the following primer 5'GAAAATCCCAGAGGGTCCAAGGATATCAAGAAGAATAAAAATGTAACC-3' and the QuikChange Lightning Mutagenesis kit (Agilent, Cat. No. 210515-5). The plasmid was digested with Not I and Nde I, and the resulting fragment was ligated in pIV-sh $\beta 1$ itg (previously modified to remove GFP). The EF1 $\alpha$ promoter was replaced with the Ubiquitin promoter in order to ensure a low expression level of GFP- $\beta 1$-integrin. All Pak constructs were kindly provided by Gary Bokoch (La Jolla, California).

Ethics statement: Mice were housed and maintained according to the University of Manchester and UK Home Office guidelines for animal research. Animals were bred under Home Office Project Licence 40/3155, and approved by the University of Manchester ethical review process. Experiments were conducted in accordance with the $\mathrm{S} 1$ killing of the Animals Scientific Procedures Act 1986.

Cell culture and transfection: Low passage FSK7 MECs (Kittrell, Oborn, and Medina 1992) were cultured in DMEM/F-12 medium (BioWhittaker; Lonza) supplemented with 2\% FBS, 5 $\mu \mathrm{g} / \mathrm{ml}$ insulin and $10 \mathrm{ng} / \mathrm{ml} \mathrm{EGF}$ at $37^{\circ} \mathrm{C}$ in a humidified atmosphere of $5 \% \mathrm{CO}_{2}$. FSK7 MECs were transfected for 3 hours by using Lipofectamine ${ }^{\circledR}$ and Plus ${ }^{\mathrm{TM}}$ Reagent (Life Technologies). After transfection, cells were cultured for $72 \mathrm{~h}$ before being replated at $10^{5}$ cells $/ \mathrm{cm}^{2}$ density on glass coverslips prior to EdU labelling, fixing and staining. HEK293T cells (ATCC) were cultured in DMEM with Ultra-glutamine (Lonza) containing 10\% FBS (Biosera) and $100 \mathrm{U} / \mathrm{ml}$ Penicillin/streptomycin. These cells were transfected with JetPEI ${ }^{\mathrm{TM}}$ 
reagent (Sigma-Aldrich). Primary MECs were isolated from 8-10 week old nulliparous ICR mice and grown on collagen-I coated coverslips as previously described (Pullan, et al. 1996). Primary MECs were cultured in growth medium containing $5 \mu \mathrm{g} / \mathrm{ml}$ insulin, $1 \mu \mathrm{g} / \mathrm{ml}$ hydrocortisone, $3 \mathrm{ng} / \mathrm{ml}$ EGF, 10\% $\mathrm{FCS}, 50 \mathrm{U} / \mathrm{ml}$ penicillin/streptomycin, $0.25 \mu \mathrm{g} / \mathrm{ml}$ fungizone, and $50 \mu \mathrm{g} / \mathrm{ml}$ gentamycin in F12 medium.

Immunofluorescence staining: Cells were fixed with $4 \%$ formaldehyde for ten minutes. After fixation, cells were permeabilised using $0.2 \%$ Triton $\mathrm{X}-100$ and blocked with $10 \%$ goat serum. Cells were sequentially incubated with primary and secondary antibodies for one hour each at room temperature, protected from light. Primary antibodies used for immunostaining were: $\beta 1$-integrin (MAB1997 Chemicon), ß1-integrin clone 12G10 (Abcam), GFP (Life Technologies), and Paxillin (BD Transduction) and Histone3 pS10 (Millipore). Secondary antibodies used were Alexa 488 anti-mouse IgG and Alexa 647 anti-rabbit IgG (Molecular Probes), Rhodamine Red-X-AffiniPure Anti-Rat IgG and Anti-Mouse IgG (Jackson ImmunoResearch Laboratories, Inc.). A solution of $4 \mu \mathrm{g} / \mathrm{ml}$ of DAPI diluted in PBS was used to stain the nuclear content. Coverslips were mounted onto glass slides with Dako Fluorescent Mounting medium. Cells were observed with a fluorescence microscope (Zeiss Axio Imager MZ HXP120C) and pictures were taken with a Hamamatsu ORCA-ER camera.

EdU proliferation assay: Cells grown on coverslips were incubated with $10 \mu \mathrm{M}$ 5-ethynyl-2'deoxyuridine (EdU) for 6 hours (for primary MECs) or 30 minutes (for FSK7). Incorporated EdU was detected by incubating the cells with an Alexa Flour 647-azide that binds to EdU in the labelled cells, using the Click-iT'TM EdU Alexa Fluor ${ }^{\mathrm{T}} 647$ Imaging Kit (Invitrogen \#C10340). This incubation was followed by immunostaining and DAPI counterstaining. The percentage of EdU-positive cells was calculated as a percentage of the total DAPI stained nuclei. For primary MECs, an average of 2000 cells was counted per experiment. For FSK7, a minimum of 100 transfected cells (expressing the fluorescent reporter gene) was counted per experiment. This number was compared to the percentage of non-transfected cells from 
the same coverslip. Statistical significance was determined by student's t-test. Error bars represent standard error of the mean (SEM).

Immunoblotting: Equivalent amounts of protein were resolved by SDS-PAGE and immunoblotted using the following antibodies: Akt pS473, NICD and myc tag (Cell Signaling), $\beta$-tubulin (Sigma), $\beta 1$-integrin (BD Transduction), V5 (AbD Serotec), GFP (Molecular Probes). This was followed by incubation with peroxidase-conjugated anti-rabbit or antimouse IgG (Jackson ImmunoResearch Laboratories, Inc.). Finally, signal was detected with a chemiluminescent substrate (Super Signal West Pico reagent, Thermo Scientific) and developed in an automatic X-ray film processor JP-33 after exposing the membrane to an Xray film (Fujifilm).

RNA extraction, cDNA synthesis and qPCR: FSK7 cells were plated on plastic and lysed with Trizol. Briefly, $1 \mathrm{ml}$ Trizol was used to lyse a $10 \mathrm{~cm}$ plate of $70 \%$ confluent FSK 7 cells and phase separated twice with chloroform. RNA was then precipitated with isopropanol and spun at $17000 \mathrm{rpm}$ for 5 minutes at $4^{\circ} \mathrm{C}$. Pellets were resuspended in $5 \mathrm{mM} \mathrm{LiCl}$ overnight at $-20^{\circ} \mathrm{C}$ and then spun at $17000 \mathrm{rpm}$ and $4^{\circ} \mathrm{C}$. Pellets were washed with $70 \%$ ethanol, dried and resuspended in RNAse free water. Samples were assessed for concentration and purity by Nanodrop spectrometer 1000 (Thermo Scientific). Synthesis of cDNA was carried out using High Capacity RNA-to-cDNA kit (Life Technology). $1 \mu \mathrm{g}$ RNA was used per cDNA reaction. Gene analysis was carried out using TaqMan ${ }^{8}$ Fast Advanced Master Mix (Life Technologies) on a StepOnePlusTM (Applied Biosystems). Each reaction was repeated in triplicate. Fluorescence was recorded and used to calculate $2-(\Delta \Delta \mathrm{CT})$ for statistical analysis.

Rac1 activation assay: Lysates from primary MECs were applied onto a multiwell plate containing a Rac1-GTP binding protein (GLisa Rac1 activity assay, Cytoskeleton, Cat. \# BK128). Active Rac1 present in the lysates was captured in the wells and detected using an anti-Rac1 antibody coupled to a colorimetric assay. Finally, absorbance was read using a Biotek® Powerwave 340 plate reader at 490nm. 
Statistical Analysis: Statistical significance was determined by Student's $t$ test for paired samples or 1-Way ANOVA with Tukey's multiple comparisons. Differences between samples were significant when $p=<0.05$. For all graphs shown, error bars represent $+/$ - standard error of the mean (SEM). 


\section{Results}

\section{FSK7 as a culture model to study the effects of $\beta 1$-integrin depletion on proliferation}

We tested whether FSK7 MECs could be used as a model to study how $\beta 1$-integrin controls proliferation. Cells were transfected either with an shRNA to target $\beta 1$-integrin or the empty vector (pVenus). To distinguish the potential off-target effects of the shRNA, a rescue vector containing the sequence of a human $\beta 1$-integrin fused to GFP and the $\operatorname{sh} \beta 1$ itg was used (Figure $1 \mathrm{~A}$ ). In this construct, GFP is in a flexible loop in the $\beta 1$ hybrid domain of $\beta 1$-integrin. The extracellular location of the fluorescent tag allows normal function and recruitment of adhesion components to the integrin tail (Rondas, et al. 2012). Four silent point mutations were introduced in this construct to prevent the shRNA from targeting the ectopic GFP- $\beta 1$ integrin mRNA. The rescue vector contained the Ubiquitin promoter to ensure a low expression level of the GFP-tagged integrin in transfected cells, because overexpressed integrins accumulate as intracellular aggregates or within the endoplasmic reticulum, and are unable to integrate into adhesion complexes (Wehrle-Haller 2007). The knockdown efficiency for endogenous $\beta 1$-integrin and the ectopic expression of GFP- $\beta 1$-integrin was confirmed by immunoblotting (Figure 1B). Co-localisation of GFP with paxillin confirmed that GFP- $\beta 1$ integrin could incorporate into adhesion sites of cells lacking endogenous $\beta 1$-integrin (Figure

S1). Additionally, we stained the cells with an antibody that recognises the active conformation of $\beta 1$-integrin (12G10 antibody). Co-localisation of the GFP signal with that of active $\beta 1$-integrins shows that our GFP-tagged integrin construct is functional.

Three days after transfection, cells were trypsinised, replated onto coverslips and left for 24 hours to attach. MECs were pulse-labelled with EdU for 30 minutes before being fixed and immunostained to detect $\beta 1$-integrin, and EdU was used as a measure of proliferation. The $\beta 1$-integrin antibody used here only recognises mouse protein (endogenous protein), so the ectopically expressed human $\beta 1$-integrin was not detected. For the MECs transfected with sh $\beta 1$ itg, we first identified the cells where $\beta 1$-integrin was depleted and then analysed their 
proliferation levels. $\beta 1$-integrin-knockdown cells proliferated less than the non-transfected cells around them (Figure 1C-D). As a control, cells transfected with the empty vector showed no difference in the proportion of proliferating cells compared to the surrounding non-transfected cells. Expression of GFP- $\beta 1$-integrin rescued the proliferation defect caused by depletion of endogenous $\beta 1$-integrin.

These results show that $\beta 1$-integrin is required for the proliferation of MECs, and that these cells constitute an appropriate model to silence $\beta 1$-integrin and study the proliferative defect arising from that depletion.

Rac1, via its ability to bind Pak, is required for MEC proliferation downstream of $\beta 1$ integrin

We have previously shown that $\beta 1$-integrin-null primary MECs from pregnant mice show decreased proliferation, along with reduced Rac1 activity and Pak phosphorylation (Jeanes, et al. 2012). This suggests that $\beta 1$-integrin controls cell cycle by activating Rac1 and Pak. We therefore inhibited Rac1 in ductal MECs and examined proliferation. MECs were isolated from nulliparous mice, cultured for 2 days, and treated with the Rac1 inhibitor EHT1864 for $20 \mathrm{~h}$, prior to EdU incorporation for $6 \mathrm{~h}$. Reduction of Rac1 activity was observed in primary cells treated with EHT1864 (Figure S2). EHT1864 binds to Rac1 and promotes the loss of bound nucleotide, rendering the GTPase inactive and unable to bind an effector (Shutes, et al. 2007). The results revealed a significant reduction of proliferation in response to EHT1864, compared to untreated cells (Figure 2A). Due to the intrinsic differences between mouse preparations, the reduction in proliferation in the primary cells was illustrated as a proportion of the proliferating cells from the untreated control.

We then tested whether a constitutively active version of Rac1 could compensate the proliferation defect of $\beta 1$-integrin depleted MECs. To do this, we used fast a cycling Rac1 containing a mutation ( $\mathrm{F} 28 \mathrm{~L}$ ) that allows it to be activated spontaneously by conferring an 
ability to exchange nucleotides rapidly and independently of GEF proteins. Fast cycling Rac1 restores the normal proliferation levels of $\beta 1$-integrin depleted MECs (Jeanes, et al. 2012). We therefore asked whether disrupting the interaction of Rac1 with one of its effectors might explain how Rac1 mediates proliferation in ductal MECs. Two Rac1 effectors have been linked to proliferation control. p67phox is a cytosolic component of the NADPH complex that interacts with Rac1 to produce ROS (Diekmann, et al. 1994). At low levels, ROS production is required for DNA synthesis in fibroblasts (Joneson and Bar-Sagi 1998; Sundaresan, et al. 1996). Another downstream Rac target, Pak, is involved with proliferation via its ability to feedback to the MAPK/Erk pathway (Coles and Shaw 2002; Slack-Davis, et al. 2003).

The $\mathrm{N} 26 \mathrm{H}$ mutation in Rac1 impairs its binding to p67phox and thus abolishes superoxide production, without interfering with Pak activation (Freeman, Abo, and Lambeth 1996). In contrast, the N43D mutation in Rac1 prevents Pak1-3 binding to the GTPase without disrupting its interaction with other effectors (Joyce, et al. 1999; Westwick, et al. 1997). We therefore introduced either of these mutations into the fast-cycling Rac1 construct to test whether interaction of Rac1 with NADPH complex and/or Pak factors is required for the regulation of proliferation in MECs.

Depleting $\beta 1$-integrin from cells reduced proliferation, which was rescued by co-expression of fast-cycling Rac1 (Figure 2B-D). The N26H-mutant Rac1 still rescued proliferation, indicating that interaction of Rac1 with p67phox is not required to mediate proliferation in MECs.

Conversely, expression of Rac1 with N43D mutation could not rescue the proliferation defect caused by $\beta 1$-integrin knockdown. This revealed that the ability of Rac1 to bind to Pak is required for MEC proliferation. Rac1 is the major Rac isoform expressed in MECs (Figure $2 \mathrm{E})$, thus suggesting that Rac1 is the main Rac isoform involved in MEC proliferation.

These results show that fast-cycling Rac1 can rescue the proliferation defect in $\beta 1$-integrin depleted MECs. This requires an intact Pak binding site, indicating that Rac1's ability to rescue proliferation depends on binding to and activating its downstream effector, Pak. 


\section{Pak kinase activity is required for MEC proliferation downstream of $\beta 1$-integrin}

To confirm the role of Pak in ductal MEC proliferation, we transfected MECs with the autoinhibitory domain of Pak (Pak AID) (Bokoch 2003; Molli, et al. 2009). As a control, we used a non-functional auto-inhibitory domain of Pak (Pak NAI), bearing the L107F mutation (Zenke, et al. 1999). Expression of Pak AID caused a similar reduction in proliferation as $\beta 1$-integrin depletion, while cells expressing Pak NAl showed similar levels of proliferation as the nontransfected MECs (Figure 3A). For these experiments, we used phospho-Histone3 staining for assessing proliferation instead of EdU incorporation. We have previously shown that both methods give similar results in experiments with FSK7 cells (Jeanes et al., 2012). This assay was the preferred method when using the Pak myc-tagged constructs, due to a better detection of the transfected cells with an Alexa 647 conjugated antibody.

To confirm the role of Pak in adhesion-mediated proliferation, a constitutively active Pak was expressed in MECs along with sh $\beta 1$ itg. This form of Pak contains the kinase domain only and lacks the auto-inhibitory domain. As a control, an inactive kinase domain with K298A mutation was used. Expression of these myc-tagged Pak constructs was confirmed in HEK293T cells - both led to synthesis of proteins of the predicted molecular weight of $42 \mathrm{kDa}$ (Figure 3B). MECs were co-transfected with sh $\beta 1$ itg and either active Pak kinase domain (CA-Pak) or kinase dead (KD-Pak) mutants. CA-Pak rescued proliferation similarly to the fast-cycling Rac1, while KD-Pak showed a similar pattern of proliferation as $\beta 1$-integrin knockdown MECs (Figure 3C). Two different isoforms of Pak are expressed in mammary epithelial cells, Pak1 and Pak2. Both are expressed at similar levels in FSK7 cells (Figure 3D). Moreover, the homology between the kinase domain and AID of Pak1 and Pak2 is 93\% and $97 \%$, respectively. Expressing the kinase domain or AID separately does not discriminate between the specific effects of Pak1 and Pak2 isoforms. Both isoforms may therefore contribute to MEC proliferation. Our findings place Pak as a crucial effector of MEC 
proliferation and open a new window to further explore the individual effects of the two Pak isoforms in this process.

These results show that an activated form of Pak can rescue the proliferation defect in $\beta 1$ integrin depleted MECs. Since Pak kinase activity is required for $\beta 1$-integrin signalling, this indicates that $\beta 1$-integrin requires the Rac1-Pak signalling axis to control normal proliferation in ductal MECs.

\section{Oncogenic ErbB2 can overcome the need for $\beta 1$-integrin in MEC proliferation}

We examined whether FSK7 cells provide a suitable model to test which oncogenes require B1-integrin for MEC proliferation. A mutated version of ErbB2 ( $v$-ErbB2, V659E) that confers oncogenic features to this protein was expressed alone or co-expressed with sh $\beta 1$ itg (Figure 4A-B). MECs expressing oncogenic ErbB2 proliferated to a similar extent as the surrounding non-transfected cells, even when $\beta 1$-integrin was depleted (Figure $4 \mathrm{C}$ ). Thus, ErbB2 is able to rescue the sh $\beta 1$ itg phenotype. These results are consistent with in vivo observations that ErbB2 mediates mammary tumour formation in $\beta 1$-integrin-null epithelium (Huck, et al. 2010). ErbB2 is a mammary oncogene and its transforming activity can be detected only when breast epithelial cells are cultured in 3D (Muthuswamy, et al. 2001). Therefore, as expected, expression of $\mathrm{v}$-ErbB2 alone did not change the proportion of proliferating MECs cultured in monolayer.

ErbB2 can activate Rac1 through phosphorylation of several GEFs, including Dock180, PRex1 and Vav1 (Sosa, et al. 2010; Laurin, et al. 2013). Thus, we hypothesised that ErbB2 may overcome the requirement of $\beta 1$-integrin for proliferation by activating Rac1 and Pak. We blocked Pak signalling by co-transfecting MECs (+/- sh $\beta 1$ itg) with Pak AID and ErbB2, and found that proliferation decreased significantly when Pak was inhibited (Figure 4C). 
These results show that $v$-ErbB2 overcomes the requirement of $\beta 1$-integrins for proliferation in mammary epithelia, and that ErbB2 needs to activate Pak in order to promote proliferation.

\section{The role of Akt in the control of MEC proliferation by $\beta 1$-integrin}

We then tested whether expression of an oncogene that does not activate Rac1 or Pak might also restore proliferation in $\beta 1$-integrin knockdown MECs. Since the PI3K/Akt pathway plays a central role in proliferation control and is deregulated in breast cancer, we used a membrane-bound form of Akt to mimic its increased signalling activity in breast cancer (Figure 5A). In HEK293T cells, myristoylated Akt appears as a higher molecular weight form than endogenous Akt. Phosphorylation of myrAkt at Serine 473 indicates that the protein is active (Figure 5B). Myristoylated Akt increased the expression levels of phosphorylated GSK3 $\beta$ when expressed in MECs, thus confirming the functionality of the protein (Figure $5 \mathrm{C}$ ). In contrast, an inactive form of myristoylated Akt (myrAkt S473A) showed lower levels of phosphorylated GSK3 $\beta$ compared to non-transfected cells. To test whether myrAkt had an effect in MEC proliferation, cells were transfected with myrAkt alone or co-transfected with myrAkt and sh $\beta 1$ itg. We found that the myrAkt was not able to rescue the impaired proliferation in cells simultaneously expressing the shRNA that targets $\beta 1$-integrin (Figure 5D).

These results contrast with the effects of $\mathrm{v}-\mathrm{ErbB} 2$, showing that oncogenic activated Akt is not sufficient to promote proliferation in the absence (or even in the presence) of $\beta 1$-integrin. Moreover, they confirm that the ability to activate the Rac1-Pak axis is required to drive proliferation in $\beta 1$-integrin depleted MECs. 


\section{Discussion}

\section{Rac1 and Pak in MEC proliferation}

Here we highlight the importance of group I Paks in MEC proliferation. Group I Paks are downstream of Rac1, which is the major Rac isoform expressed in MECs (Figure 2E). Pak expression has been linked to proliferative changes in the mammary gland. Pak induces transcription of cyclin D1 through an NFkB-dependent pathway during lactation, and is a key link between integrin signalling and growth factor receptors (GFRs) (Balasenthil, et al. 2004; del Pozo, et al. 2000). It phosphorylates Mek1 and provides sustained Erk activation (SlackDavis, et al. 2003). We previously showed that in MECs isolated from pregnant mice, Pak mediates Erk nuclear translocation downstream of $\beta 1$-integrin (Jeanes, et al. 2012). Here, we show for the first time that Pak is involved with the proliferation in ductal MECs derived from nulliparous mice. Thus, in both alveolar and ductal MECs, Rac1 and Pak are required for proliferation (Figure 6A).

Pak was needed to restore the proliferative defect in $\beta 1$-integrin knockdown MECs. Furthermore, inhibiting endogenous Pak by expressing the AID peptide blocked proliferation. This peptide has been previously used to block Pak signalling and proliferation of breast cancer cells (Mira, et al. 2000). However, a constitutively active Pak does not restore proliferation of fibroblasts expressing Pak AID, revealing an alternative pathway by which Pak controls proliferation independently of its kinase activity (Thullberg, et al. 2007). Indeed, Pak acts as a scaffold to recruit Raf, MEK, and ERK to adhesion complexes, thereby facilitating Erk activation (Sundberg-Smith, et al. 2005; Wang, et al. 2013). Our results also indicate that Pak activates a separate downstream effector for its effects on proliferation. 


\section{Oncogene dependence on $\beta 1$-integrin for MEC proliferation}

The FSK7 2D model provides a robust method to determine whether an oncogene is able to overcome the $\beta 1$-integrin-requirement for proliferation. Interestingly we reveal that oncogenes have differential requirements for $\beta 1$-integrin to drive proliferation. For example, ErbB2 activates the Rac1-Pak axis in the absence of $\beta 1$-integrin, but Akt cannot drive proliferation without integrins. Thus, not all oncogenes can overcome a requirement for $\beta 1$ integrin. In addition, adequate activation of MAPK/Erk orchestrated by GFRs and $\beta 1$-integrin is essential to induce MEC proliferation. This supports a hypothesis in which $\beta 1$-integrin contributes to cell cycle progression through the MAPK/Erk pathway.

Our MEC model resembles transformation of a single cell by overexpressing an oncogene, which is surrounded by normal cells. Indeed, the low transfection rate achieved is an advantage for these studies. In other MEC types such as MCF10A, if only one cell expresses the oncogene (e.g. ErbB2) in a growth arrested acinar structure, it translocates to the lumen and drives proliferation, resembling the characteristics of ductal carcinoma of the breast (Walker 2014; Debnath, Muthuswamy, and Brugge 2003; Leung and Brugge 2012).

FSK7s behave similarly to primary MECs isolated from nulliparous mice and show luminal epithelial characteristics in normal 2D cultures. This contrasts with MCF10A, which express markers of basal epithelial cells but are unable to form proper tight junctions. The cells display impaired cellular polarisation, and they are negative for oestrogen receptor (Debnath, Muthuswamy, and Brugge 2003). In our FSK7 model, ErbB2 did not require $\beta 1$-integrin to induce cell proliferation, consistent with previous findings from in vivo and in vitro models (Huck, et al. 2010; Arias-Romero, et al. 2010). Moreover, the fact that myrAkt was not sufficient to drive proliferation in cells lacking $\beta 1$-integrin reveals that the model distinguishes between oncogenes that require $\beta 1$-integrin from those that do not. Therefore, the 2D FSK7 model constitutes a straightforward way to assess whether oncogenes rely on an additional input from $\beta 1$-integrin to promote proliferation. 


\section{$\alpha$-integrins in mammary cancer}

$\beta 1$-integrin associates with $\alpha 2, \alpha 3$ and $\alpha 6$-integrins in luminal MECs (Faraldo, et al. 2000). The absence of $\alpha 3$ and $\alpha 6$ integrins does not affect mammary gland growth, suggesting that $\alpha 2 \beta 1$ integrin might act as the principal heterodimer controlling proliferation (Klinowska, et al. 2001). However, during breast cancer progression, integrins acquire different functions to those in normal mammary gland development. For example, $\alpha 6 \beta 4$ integrin is dispensable for normal growth, but forms complexes with ErbB2 to promote hyperproliferation in tumours (Klinowska, et al. 2001; Guo, et al. 2006).

Deleting $\alpha 2$ integrin does not affect MEC tumour growth in mice overexpressing ErbB2, consistent with $\beta 1$-integrin not being required for ErbB2-tumours (Ramirez, et al. 2011; Huck, et al. 2010). However, $\alpha 2$ integrin is a metastasis suppressor. Thus after tumour onset, other $\beta 1$-integrin heterodimers may contribute to tumour progression: for example, $\alpha 3$ and $\alpha 6$ integrin are both linked to increased metastatic potential (Wang, et al. 2011; Shirakihara, et al. 2013). Moreover, $\alpha 3 \beta 1$ integrin promotes transformation, and basal breast cancer cells that are characterised by an invasive phenotype need $\alpha 3$ and $\alpha 6$ integrins to induce migration (Cagnet, et al. 2014; Yang, et al. 2008; Mitchell, et al. 2010). Thus $\beta 1$-integrins have a key role not only in normal mammary growth, but also during cancer development ( $\mathrm{Li}$, et al. 2005).

\section{ErbB2 and the Rac1-Pak axis}

Our results showing that ErbB2 can drive proliferation in the absence of $\beta 1$-integrin are consistent with the observation that mice overexpressing ErbB2 in the mammary epithelium do not require $\beta 1$-integrin to form tumours (Huck, et al. 2010). We now reveal that ErbB2 requires Pak signalling for proliferation in $\beta 1$-integrin depleted cells (Figure 6B). Rac and Pak 
activation downstream of ErbB2 has been mainly linked to migration and invasion. For example, ErbB2 activates Rac1 to promote cell motility in several breast cancer cell lines (Wang, et al. 2006). Studies using in vivo models suggest that ErbB2 requires the Rac GEFs Tiam1 or Dock180 to mediate tumour growth, as their absence reduces the number of tumours in MMTV-ErbB2 mice (Strumane, et al. 2009; Laurin, et al. 2013). The GEF P-Rex1 also facilitates the transforming effects of ErbB2 in breast cancer cells (Sosa, et al. 2010).

Thus, ErbB2 utilises different GEFs in order to activate Rac1 during transformation. In the future, we aim to identify the GEF involved in Rac1 signalling downstream of $\beta 1$-integrin and to determine whether ErbB2 uses the same GEF(s). This may reveal what GEFs are used by ErbB2 to promote proliferation in cells with no other mutations.

Another possibility is that ErbB2 acts downstream of B1-integrin to control proliferation. Indeed, integrins activate GFRs in the absence of GFR ligands_(Walker and Assoian 2005) Additionally, B1-integrin can co-precipitate with ErbB2 in breast cancer cells (Falcioni, et al. 1997). This suggests that these two receptors might be in close proximity in the cell, which could be important to recruit adaptors and effectors for signalling. In MCF10A MECs, ErbB2 colocalises with the Rac GEF Vav2 and active Rac1 at cell protrusions after treatment with _(Wang, et al. 2006). Although it is not clear whether B1-integrin could response by itself, ErbB2 can activate the Rac1-Pak pathway by recruiting Rac GEFs in collaboration with other signalling receptors_(Hynes and Gattelli 2011). This leaves open that $\beta 1$-integrin initiates the signalling axis comprised of

A)._Rac1 and Pak1, but not Pak2, are required for ErbB2-mediated hyperproliferation in MCF10A MECs (Arias-Romero, et al. 2010; Arias-Romero, et al. 2013). For our work, Pak AID was used to inhibit Pak signalling, which confirms the importance of Pak downstream of an activated ErbB2. Activated ErbB2 may surpass the need for $\beta 1$ integrin via the Rac1-Pak pathway in vivo, and we show that this also occurs in 2D culture. Indeed, the FSK7 2D model presents advantages for this assay, due to the shorter time needed to perform the analyses. 


\section{Summary}

In summary, our study highlights the pivotal role that Rac1 and Pak play, not only in normal but also in oncogene-driven proliferation. Oncogenes with the ability to signal to Rac1 might be able to overcome the requirement for $\beta 1$-integrin in MECs to promote proliferation. In the future, it would be valuable to test this hypothesis with other oncogenes.

\section{Conclusions}

Deletion of the beta1-integrin gene reveals a central role for integrins in the cell cycle of breast ductal epithelia, which occurs via Rac1 and Pak signalling. The proliferative requirement of integrins can be overcome by constitutively-active ErbB2, but not by other oncogenes such as Akt.

a) $\beta 1$-integrin signalling is required for the proliferation of breast epithelia.

b) Breast epithelia only express Rac1, but not Rac2 or Rac3, and the former is required for proliferation.

c) Inhibiting Pak signalling blocks epithelial proliferation; a constitutively active Pak can rescue the integrin-dependence of cell cycle.

d) The integrin-dependence of mammary cell proliferation can be rescued by an activated ErbB2, which requires Pak for this function.

e) Akt signalling is not sufficient to rescue integrin-depleted epithelia, revealing a differential requirement for $\beta 1$-integrin to promote proliferation in cells expressing oncogenic ErbB2 or Akt. 


\section{Declarations}

Ethical Approval and Consent to participate: Not applicable.

Consent for publication: The funders had no role in decision to publish, or preparation of the manuscript.

Competing interests: The authors declare no conflict of interest.

Funding: This work was supported by Wellcome Trust core funding for The Wellcome Trust Centre for Cell-Matrix Research (Grant 088785/Z/09/Z). PML was supported by the Mexican National Council for Science and Technology (CONACyT) and the General Direction of International Relations of the Mexican Ministry of Public Education (SEP). The funders had no role in study design, data collection and analysis, decision to publish, or preparation of the manuscript.

Authors' contributions: PML, AU, HS, AW and SO conducted the experimental work. CHS, PML, AG and KB were involved in experimental planning and study design. PML and $\mathrm{CHS}$ wrote the manuscript. All authors read and agreed to the manuscript in its submitted form. 


\section{References}

Arias-Romero, L. E., et al. 2010. "A Rac-Pak Signaling Pathway Is Essential for Erbb2-Mediated Transformation of Human Breast Epithelial Cancer Cells." Oncogene 29, no. 43 (Oct): 58395849. http://dx.doi.org/10.1038/onc.2010.318.

Arias-Romero, Luis E., et al. 2013. "Pak1 Kinase Links Erbb2 to Beta-Catenin in Transformation of Breast Epithelial Cells." Cancer Research 73, no. 12 (Jun 15): 3671-3682. http://dx.doi.org/10.1158/0008-5472.can-12-4453.

Balasenthil, S., et al. 2004. "P21-Activated Kinase-1 Signaling Mediates Cyclin D1 Expression in Mammary Epithelial and Cancer Cells." Journal of Biological Chemistry 279, no. 2 (Jan 9): 1422-1428. http://dx.doi.org/10.1074/jbc.M309937200.

Bokoch, G. M. 2003. "Biology of the P21-Activated Kinases." Annual Review of Biochemistry 72 (2003): 743-781. http://dx.doi.org/10.1146/annurev.biochem.72.121801.161742.

Cagnet, S., et al. 2014. "Signaling Events Mediated by Alpha3beta1 Integrin Are Essential for Mammary Tumorigenesis." Oncogene 33, no. 34 (2014-Aug-21): 4286-95. http://dx.doi.org/10.1038/onc.2013.391.

Carpten, John D., et al. 2007. "A Transforming Mutation in the Pleckstrin Homology Domain of Akt1 in Cancer." Nature 448, no. 7152 (Jul 26): 439-U1. http://dx.doi.org/10.1038/nature05933.

Coles, L. C., and P. E. Shaw. 2002. "Pak1 Primes Mek1 for Phosphorylation by Raf-1 Kinase During Cross-Cascade Activation of the Erk Pathway." Oncogene 21, no. 14 (Mar 28): 2236-2244. http://dx.doi.org/10.1038/sj/onc/1205302.

Debnath, J., S. K. Muthuswamy, and J. S. Brugge. 2003. "Morphogenesis and Oncogenesis of Mcf-10a Mammary Epithelial Acini Grown in Three-Dimensional Basement Membrane Cultures." Methods 30, no. 3 (Jul): 256-268. http://dx.doi.org/10.1016/s1046-2023(03)00032-x.

del Pozo, M. A., et al. 2000. "Adhesion to the Extracellular Matrix Regulates the Coupling of the Small Gtpase Rac to Its Effector Pak." Embo Journal 19, no. 9: 2008-2014.

Diekmann, D., et al. 1994. "Interaction of Rac with P67(Phox) and Regulation of Phagocytic Nadph Oxidase Activity." Science 265, no. 5171 (Jul 22): 531-533. http://dx.doi.org/10.1126/science.8036496.

dos Santos, Petra Barros, et al. 2012. "Beta 1 Integrin Predicts Survival in Breast Cancer: A Clinicopathological and Immunohistochemical Study." Diagnostic Pathology 7 (Aug 16). http://dx.doi.org/10.1186/1746-1596-7-104. 
Falcioni, R., et al. 1997. "Alpha 6 Beta 4 and Alpha 6 Beta 1 Integrins Associate with Erbb-2 in Human Carcinoma Cell Lines." Experimental Cell Research 236, no. 1 (Oct 10): 76-85. http://dx.doi.org/10.1006/excr.1997.3695.

Faraldo, M. M., et al. 2000. "Development of Mammary Gland Requires Normal Beta 1-Integrin Function." Biology of the Mammary Gland 480: 169-174.

Freeman, J. L., A. Abo, and J. D. Lambeth. 1996. "Rac "Insert Region" Is a Novel Effector Region That Is Implicated in the Activation of Nadph Oxidase, but Not Pak65." Journal of Biological Chemistry 271, no. 33 (Aug 16): 19794-19801.

Glukhova, Marina A., and Charles H. Streuli. 2013. "How Integrins Control Breast Biology." Current opinion in cell biology 25, no. 5 (2013-Oct): 633-41. http://dx.doi.org/10.1016/j.ceb.2013.06.010.

Guo, W. J., et al. 2006. "Beta 4 Integrin Amplifies Erbb2 Signaling to Promote Mammary Tumorigenesis." Cell 126, no. 3: 489-502. http://dx.doi.org/10.1016/j.cell.2006.05.047.

Huck, L., et al. 2010. "Beta 1-Integrin Is Dispensable for the Induction of Erbb2 Mammary Tumors but Plays a Critical Role in the Metastatic Phase of Tumor Progression." Proceedings of the National Academy of Sciences of the United States of America 107, no. 35: 15559-15564. http://dx.doi.org/10.1073/pnas.1003034107.

Hynes, N. E., and H. A. Lane. 2005. "Erbb Receptors and Cancer: The Complexity of Targeted Inhibitors (Vol 5, Pg 341, 2005)." Nature Reviews Cancer 5, no. 7. http://dx.doi.org/10.1038/nrc1667.

Hynes, Nancy E., and Albana Gattelli. 2011. "P-Rex1, a Guanine Exchange Factor That Is Overexpressed in Breast Cancer, Is a Convergence Node for Erbb and Cxcr4 Signaling." Molecular Cell 41, no. 1 (Jan 7): 5-7. http://dx.doi.org/10.1016/j.molcel.2010.12.024.

Jeanes, Alexa I., et al. 2012. "Specific Beta-Containing Integrins Exert Differential Control on Proliferation and Two-Dimensional Collective Cell Migration in Mammary Epithelial Cells." Journal of Biological Chemistry 287, no. 29 (Jul 13): 24103-24112. http://dx.doi.org/10.1074/jbc.M112.360834.

Joneson, T., and D. Bar-Sagi. 1998. "A Rac1 Effector Site Controlling Mitogenesis through Superoxide Production." Journal of Biological Chemistry 273, no. 29 (Jul 17). http://dx.doi.org/10.1074/jbc.273.29.17991.

Joyce, D., et al. 1999. "Integration of Rac-Dependent Regulation of Cyclin D1 Transcription through a Nuclear Factor-Kappa B-Dependent Pathway." Journal of Biological Chemistry 274, no. 36 (Sep 3): 25245-25249. http://dx.doi.org/10.1074/jbc.274.36.25245. 
Kim, M. S., et al. 2008. "Mutational Analysis of Oncogenic Akt E17k Mutation in Common Solid Cancers and Acute Leukaemias." British Journal of Cancer 98, no. 9 (May 5): 1533-1535. http://dx.doi.org/10.1038/sj.bjc.6604212.

Kittrell, F. S., C. J. Oborn, and D. Medina. 1992. "Development of Mammary Preneoplasias Invivo from Mouse Mammary Epithelial-Cell Lines Invitro." Cancer Research 52, no. 7 (Apr 1): 19241932.

Klinowska, T. C. M., et al. 2001. "Epithelial Development and Differentiation in the Mammary Gland Is Not Dependent on Alpha 3 or Alpha 6 Integrin Subunits." Developmental Biology 233, no. 2 (May 15): 449-467. http://dx.doi.org/10.1006/dbio.2001.0204.

Laurin, Melanie, et al. 2013. "Rac-Specific Guanine Nucleotide Exchange Factor Dock1 Is a Critical Regulator of Her2-Mediated Breast Cancer Metastasis." Proceedings of the National Academy of Sciences of the United States of America 110, no. 18 (Apr 30): 7434-7439. http://dx.doi.org/10.1073/pnas.1213050110.

Leung, Cheuk T., and Joan S. Brugge. 2012. "Outgrowth of Single Oncogene-Expressing Cells from Suppressive Epithelial Environments." Nature 482, no. 7385 (Feb 16): 410-U160. http://dx.doi.org/10.1038/nature10826.

Li, N., et al. 2005. "Beta 1 Integrins Regulate Mammary Gland Proliferation and Maintain the Integrity of Mammary Alveoli." Embo Journal 24, no. 11: 1942-1953. http://dx.doi.org/10.1038/sj.emboj.7600674.

Mira, J. P., et al. 2000. "Endogenous, Hyperactive Rac3 Controls Proliferation of Breast Cancer Cells by a P21-Activated Kinase-Dependent Pathway." Proceedings of the National Academy of Sciences of the United States of America 97, no. 1 (Jan 4): 185-189. http://dx.doi.org/10.1073/pnas.97.1.185.

Mitchell, Kara, et al. 2010. "Suppression of Integrin Alpha 3 Beta 1 in Breast Cancer Cells Reduces Cyclooxygenase-2 Gene Expression and Inhibits Tumorigenesis, Invasion, and Cross-Talk to Endothelial Cells." Cancer Research 70, no. 15 (Aug 1): 6359-6367. http://dx.doi.org/10.1158/0008-5472.can-09-4283.

Molli, P. R., et al. 2009. "Pak Signaling in Oncogenesis." Oncogene 28, no. 28 (Jul 16): 2545-2555. http://dx.doi.org/10.1038/onc.2009.119.

Muthuswamy, S. K., et al. 2001. "Erbb2, but Not Erbb1, Reinitiates Proliferation and Induces Luminal Repopulation in Epithelial Acini." Nature Cell Biology 3, no. 9 (Sep): 785-792. http://dx.doi.org/10.1038/ncb0901-785.

Parikh, Chaitali, et al. 2012. "Disruption of Ph-Kinase Domain Interactions Leads to Oncogenic Activation of Akt in Human Cancers." Proceedings of the National Academy of Sciences of the United States of America 109, no. 47 (Nov 20): 19368-19373. http://dx.doi.org/10.1073/pnas.1204384109. 
Penuel, E., R. W. Akita, and M. X. Sliwkowski. 2002. "Identification of a Region within the Erbb2/Her2 Intracellular Domain That Is Necessary for Ligand-Independent Association." Journal of Biological Chemistry 277, no. 32 (Aug 9): 28468-28473. http://dx.doi.org/10.1074/jbc.M202510200.

Pullan, S., et al. 1996. "Requirement of Basement Membrane for the Suppression of Programmed Cell Death in Mammary Epithelium." Journal of Cell Science 109: 631-642.

Ramirez, Norma E., et al. 2011. "The Alpha(2)Beta(1) Integrin Is a Metastasis Suppressor in Mouse Models and Human Cancer." Journal of Clinical Investigation 121, no. 1 (Jan): 226-237. http://dx.doi.org/10.1172/jci42328.

Rondas, Dieter, et al. 2012. "Novel Mechanistic Link between Focal Adhesion Remodeling and Glucose-Stimulated Insulin Secretion." Journal of Biological Chemistry 287, no. 4 (Jan 20): 2423-2436. http://dx.doi.org/10.1074/jbc.M111.279885.

Shirakihara, Takuya, et al. 2013. "Identification of Integrin Alpha 3 as a Molecular Marker of Cells Undergoing Epithelial-Mesenchymal Transition and of Cancer Cells with Aggressive Phenotypes." Cancer Science 104, no. 9 (Sep): 1189-1197. http://dx.doi.org/10.1111/cas.12220.

Shutes, Adam, et al. 2007. "Specificity and Mechanism of Action of Eht 1864, a Novel Small Molecule Inhibitor of Rac Family Small Gtpases." Journal of Biological Chemistry 282, no. 49 (Dec 7): 35666-35678. http://dx.doi.org/10.1074/jbc.M703571200.

Slack-Davis, J. K., et al. 2003. "Paki Phosphorylation of Mek1 Regulates Fibronectin-Stimulated Mapk Activation." Journal of Cell Biology 162, no. 2: 281-291. http://dx.doi.org/10.1083/jcb.200212141.

Slamon, D. J. 1987. "Protooncogenes and Human Cancers." New England Journal of Medicine 317, no. 15 (Oct 8): 955-957. http://dx.doi.org/10.1056/nejm198710083171509.

Sosa, Maria Soledad, et al. 2010. "Identification of the Rac-Gef P-Rex1 as an Essential Mediator of Erbb Signaling in Breast Cancer." Molecular Cell 40, no. 6 (Dec 22): 877-892. http://dx.doi.org/10.1016/j.molcel.2010.11.029.

Strumane, K., et al. 2009. "Tiam1-Deficiency Impairs Mammary Tumor Formation in Mmtv-C-Neu but Not in Mmtv-C-Myc Mice." Journal of Cancer Research and Clinical Oncology 135, no. 1 (Jan): 69-80. http://dx.doi.org/10.1007/s00432-008-0437-8.

Sundaresan, M., et al. 1996. "Regulation of Reactive-Oxygen-Species Generation in Fibroblasts by Rac1." Biochemical Journal 318 (Sep 1): 379-382. 
Sundberg-Smith, L. J., et al. 2005. "Adhesion Stimulates Direct Pak1/Erk2 Association and Leads to Erk-Dependent Pak1 Thr(212) Phosphorylation." Journal of Biological Chemistry 280, no. 3 (Jan 21): 2055-2064. http://dx.doi.org/10.1074/jbc.M406013200.

Thullberg, M., et al. 2007. "The Kinase-Inhibitory Domain of P21-Activated Kinase 1 (Pak1) Inhibits Cell Cycle Progression Independent of Pak1 Kinase Activity." Oncogene 26, no. 12 (Mar): 1820-1828. http://dx.doi.org/10.1038/sj.onc.1209983.

Viglietto, G., et al. 2002. "Cytoplasmic Relocalization and Inhibition of the Cyclin-Dependent Kinase Inhibitor P27(Kip1) by Pkb/Akt-Mediated Phosphorylation in Breast Cancer." Nature Medicine 8, no. 10 (Oct): 1136-1144. http://dx.doi.org/10.1038/nm762.

Walker, J. L., and R. K. Assoian. 2005. "Integrin-Dependent Signal Transduction Regulating Cyclin D1 Expression and G1 Phase Cell Cycle Progression." Cancer and Metastasis Reviews 24, no. 3: 383-393. http://dx.doi.org/10.1007/s10555-005-5130-7.

Walker, Scott. 2014. "The Role of Focal Adhesion Kinase in Mammary Epithelial Cell Tumorigenesis and Survival " The University of Manchester.

Wang, Shizhen Emily, et al. 2006. "Her2/Neu (Erbb2) Signaling to Rac1-Pak1 Is Temporally and Spatially Modulated by Transforming Growth Factor Beta." Cancer Research 66, no. 19 (Oct 1): 9591-9600. http://dx.doi.org/10.1158/0008-5472.can-06-2071.

Wang, Yanfang, et al. 2011. "Integrin Subunits Alpha5 and Alpha6 Regulate Cell Cycle by Modulating the Chk1 and Rb/E2f Pathways to Affect Breast Cancer Metastasis." Molecular Cancer 10 (Jul 13). http://dx.doi.org/10.1186/1476-4598-10-84.

Wang, Zhipeng, et al. 2013. "P21-Activated Kinase 1 (Pak1) Can Promote Erk Activation in a KinaseIndependent Manner." Journal of Biological Chemistry 288, no. 27 (Jul 5): 20093-20099. http://dx.doi.org/10.1074/jbc.M112.426023.

Wehrle-Haller, Bernhard. 2007. "Analysis of Integrin Dynamics by Fluorescence Recovery after Photobleaching." Methods in molecular biology (Clifton, N.J.) 370 (2007): 173-202.

Westwick, J. K., et al. 1997. "Rac Regulation of Transformation, Gene Expression, and Actin Organization by Multiple, Pak-Independent Pathways." Molecular and Cellular Biology 17, no. 3 (Mar): 1324-1335.

White, D. E., et al. 2004. "Targeted Disruption of Beta 1-Integrin in a Transgenic Mouse Model of Human Breast Cancer Reveals an Essential Role in Mammary Tumor Induction." Cancer Cell 6, no. 2: 159-170.

Yang, Xiuwei H., et al. 2008. "Cd151 Accelerates Breast Cancer by Regulating Alpha(6) Integrin Function, Signaling, and Molecular Organization." Cancer Research 68, no. 9 (May 1): 32043213. http://dx.doi.org/10.1158/0008-5472.can-07-2949. 
Zenke, F. T., et al. 1999. "Identification of a Central Phosphorylation Site in P21-Activated Kinase Regulating Autoinhibition and Kinase Activity." Journal of Biological Chemistry 274, no. 46 (Nov 12): 32565-32573. http://dx.doi.org/10.1074/jbc.274.46.32565.

Zhang, Xinbo, et al. 2011. "Akt, Foxo and Regulation of Apoptosis." Biochimica Et Biophysica ActaMolecular Cell Research 1813, no. 11 (Nov): 1978-1986. http://dx.doi.org/10.1016/j.bbamcr.2011.03.010.

Zutter, M. M., H. R. Krigman, and S. A. Santoro. 1993. "Altered Integrin Expression in Adenocarcinoma of the Breast - Analysis by in Situ Hybridization." American Journal of Pathology 142, no. 5: 1439-1448.

Zutter, M. M., G. Mazoujian, and S. A. Santoro. 1990. "Decreased Expression of Integrin Adhesive Protein Receptors in Adenocarcinoma of the Breast." American Journal of Pathology 137, no. 4: 863-870. 


\section{Figure captions}

Figure 1. GFP-tagged $\beta 1$-integrin rescues the proliferation defect caused by $\beta 1$ integrin depletion in MECs.

A) Schematic representation of the DNA constructs used. To knockdown $\beta 1$-integrin, an shRNA sequence was cloned into plV-Venus under the control of the $\mathrm{H} 1$ promoter $(\operatorname{sh} \beta 1 \mathrm{itg})$. For the rescue vector ( $\operatorname{sh} \beta 1 \mathrm{itg}+\mathrm{GFP}-\beta 1 \mathrm{itg})$, the sequence of the human $\beta 1$-integrin fused to GFP was cloned into pIV-Venus containing shRNA to target endogenous mouse $\beta 1$-integrin. Expression of GFP- $\beta 1$-integrin is under the control of the Ubiquitin promoter. The target region of sh $\beta 1$ itg is indicated in the diagram.

B) Immunoblots showing the knockdown of endogenous $\beta 1$-integrin and the ectopic expression of the GFP- 31 -integrin. FSK7 MECs were transfected either with the empty vector (pVenus) sh $\beta 1$ itg or sh $\beta 1$ itg + GFP- $\beta 1$ itg. After three days, cells were sorted for GFP expression and collected in lysis buffer. Cell lysates were subjected to immunoblotting using antibodies to detect $\beta 1$-integrin, GFP and tubulin.

C) Graph showing the percentage of EdU positive cells in transfected FSK7 cells $(n=3)$. MECs were transfected either with an empty vector ( $p$ Venus), sh $\beta 1$-integrin alone (sh $\beta 1$ itg), or sh $\beta 1$-integrin and a human $\beta 1$-integrin fused to GFP ( $\operatorname{sh} \beta 1$ itg + GFP$\beta 1$ itg). Three days after transfection, cells were replated onto coverslips and cultured for additional 24 hours. Cells were incubated for 30 minutes with EdU, before being fixed and stained to detect EdU incorporation. At least 100 transfected cells were counted to quantify the percentage of EdU positive cells for each condition. The percentage of proliferating non-transfected cells was quantified in at least 500 cells. Statistical significance was determined by Student's $t$ test for paired samples (** indicates $p=0.018$ ). Error bars in the graph represent standard error of the mean. 
D) Representative images of immunofluorescence pictures used in quantification of EdU positive cells in C. Insets of the sh $\beta 1$ itg + GFP- $\beta 1$ itg transfected cell show expression of GFP- $\beta 1$-integrin localised at the plasma membrane. Scale bar: $15 \mu \mathrm{m}$.

\section{Figure 2. $\beta 1$-integrin promotes proliferation in MECs via Rac1.}

A) Inhibition of Rac1 decreases proliferation in MECs. MECs were isolated from ICR mice and cultured on collagen I. Two days after isolation, MECs were treated with the Rac1 inhibitor EHT1864 for 20 hours. Then, MECs were incubated with EdU for 6 hours and stained for incorporated EdU. At least 1700 cells were counted for each condition $(n=2)$. Proliferation rates are shown as the proportion of EdU positive cells from the inhibitor-treated cells compared to the totality of positive cells from the untreated cells. Statistical significance was determined using t-test for paired samples and error bars represent standard error of the mean.

B) Schematic representation of the GFP-Rac1 mutant vectors. In both vectors, fast cycling Rac1 is carrying point mutations to disrupt the binding sites for either p67phox (RacN26H) or Pak (RacN43D).

C) Immunoblots showing expression of Rac1 mutants in FSK7 MECs. Cells were transfected with each of the Rac1 mutants and the GFP-expressing cells were sorted and collected three days post transfection. Collected MECs were cultured for additional 24 hours before lysing and harvesting for protein analysis by immunoblotting. Blots were probed with anti-GFP and anti- $\beta 1$-integrin antibodies.

D) Proliferation of FSK7 MECs expressing Rac1 mutants. MECs were transfected with pVenus containing the $\beta 1$-integrin-specific shRNA and the Rac1 mutant vectors. Three days after transfection, cells were trypsinised, replated onto coverslips and cultured for 24 hours. Then, MECs were labelled with EdU, fixed and immunostained to detect EdU incorporation and $\beta 1$-integrin. At least 100 transfected cells were counted to determine the percentage of proliferating cells. This percentage was compared to the percentage of EdU-positive cells in non-transfected control cells ( $n=$ 
3). Statistical significance was determined by student's test. Error bars represent standard error of the mean (SEM).

E) Rac1 is the predominantly expressed Rac isoform in FSK7 MECs. FSK7 cells grown on plastic express significantly more Rac1 relative to other isoforms. Expression was determined by $\mathrm{qPCR}\left(n=3 ;{ }^{* *} \mathrm{p}<0.01,{ }^{* * *} \mathrm{p}<0.0001 ; 1\right.$-Way ANOVA with Tukey's multiple comparisons).

\section{Figure 3. $\beta 1$-integrin promotes proliferation in MECs via Pak.}

A) Blocking Pak signalling decreases proliferation of MECs. FSK7 cells were transfected with either the empty vector (pVenus), sh $\beta 1$ itg, fast cycling Rac1 $+\operatorname{sh} \beta 1$ itg, the autoinhibitory domain of Pak (Pak AID) or a non-autoinhibitory domain (Pak NAI). Both Pak constructs were tagged with the myc epitope. Two days after transfection, cells were trypsinised, plated onto coverslips and cultured for an additional day. Then, cells were fixed and immunostained with anti- $\beta 1$-integrin, anti-phospho-Histone $\mathrm{H} 3$ and anti-myc antibodies. The percentage of $\mathrm{pH} 3$ positive cells was quantified for transfected and non-transfected cells $(n=3)$. Statistical significance was determined by student's test. Error bars represent standard error of the mean (SEM).

B) Immunoblots showing expression of Pak constructs. HEK-293T cells were transfected with a myc-tagged constitutively active Pak (CA Pak) and a kinase dead Pak (KD Pak). Two days after transfection, cells were lysed and harvested for protein analysis by immunoblotting. Blots were probed with anti-myc tag antibody. The line separates non-adjacent bands from the same blot.

C) Proliferation of FSK7 MECs cotransfected with shß1itg and Rac, CA Pak, or KD Pak. Three days after transfection, MECs were replated onto coverslips and cultured for 24 hours before fixation and immunostaining to detect $\mathrm{p}$-Histone3. The graph shows the percentage of $\mathrm{pH} 3$ positive cells in transfected and non-transfected cells $(n=3)$. 
Statistical significance was determined by student's test. Error bars represent standard error of the mean (SEM).

D) FSK7 cells express similar levels of Pak isoforms 1 and 2. Immunoblots show protein expression of Pak1 and Pak2 in FSK7 cells. Actin was used as a loading control.

Figure 4. Oncogenic ErbB2 overcomes the need for $\beta 1$-integrin to drive MEC proliferation.

A) Schematic representation of the ErbB2 vectors. In both plasmids, v-ErbB2-2A-GFP is downstream of EF1 $\alpha$ promoter and GFP and ErbB2 are expressed as separate proteins due to the presence of a self-cleaving $2 \mathrm{~A}$ sequence.

B) Immunoblot showing expression of v-ErbB2-V5-shß1itg in HEK-293T cells. Cells were transfected with the plasmid and harvested for protein analysis 48 hours after transfection. Cell lysates were resolved by SDS-PAGE, transferred to a membrane and immunoblotted with anti-V5 and anti- $\beta 1$-integrin antibodies. $\beta$-tubulin was used as a loading control.

C) EdU incorporation in FSK7 cells expressing v-ErbB2-V5-shß1itg. MECs were transfected as indicated: empty vector (pVenus) $\operatorname{sh} \beta 1$-integrin ( $\operatorname{sh} \beta 1$ itg), a mutated form of ErbB2 with or without sh $\beta 1$ itg, and with or without Pak autoinhibitory domain (Pak AID). 3 days after transfection, cells were trypsinised, plated onto coverslips and cultured for additional 24 hours before being pulse-labelled with EdU. EdU incorporation was quantified in at least 100 transfected cells and untransfected control cells. The graph shows the percentage of EdU positive cells $(n=3)$. Statistical significance was determined by student's test. Error bars in the graph represent standard error of the mean (SEM). There was no significant difference between the proliferation rates in ErbB2 + Pak AID cells and ErbB2 + shß1itg + Pak AID cells. This indicates that the proliferation defect observed in Pak AID transfected cells is

\section{independent on the abundance of $\beta 1$ integrin.}


Figure 5. myrAkt is not able to overcome the $\beta 1$-integrin to drive MEC proliferation.

A) Schematic representation of the vector used to express a membrane-targeted Akt (myrAkt). The EF1 $\alpha$ promoter drives expression of myrAkt and GFP as separate proteins due to the presence of a self-cleaving $2 \mathrm{~A}$ sequence.

B) Immunoblot showing expression of myrAkt in transfected cells. HEK-293T cells transiently expressing myrAkt were lysed 48 hours post transfection. Cell lysates were subsequently analysed by immunoblotting using antibodies to detect GFP, total and phosphorylated Akt. Equal loading of samples was confirmed by equivalent $\beta$ tubulin.

C) FSK7 MECs were transfected with an active (myrAkt) or an inactive form of Akt (myrAkt S473A). Cells were lysed and harvested for protein expression. Immunoblot shows expression of phosphorylated GSK3 $\beta$ Ser9, which is an AKT downstream effector. Vinculin was used as a loading control.

D) EdU incorporation in FSK7 cells expressing myrAkt. MECs were transfected or cotransfected with different plasmids as indicated: empty vector ( $p$ Venus), sh $\beta 1$-integrin (sh $\beta 1$ itg) and myristoylated Akt (Akt). Three days after transfection, cells were trypsinised, plated onto coverslips and cultured for additional 24 hours. Then, MECs were pulse-labelled with EdU before fixation and immunostaining. EdU incorporation was quantified in at least 100 transfected cells and untransfected control cells. The graph shows the percentage of EdU positive cells $(n=2)$. Statistical significance was determined by student's test. Error bars represent standard error of the mean (SEM).

\section{Figure 6. Diagram showing the proposed molecular model.}


A) $\beta 1$-integrin modulates MEC proliferation via Rac1-Pak signalling. $\beta 1$-integrin recruits Rac1 and Pak to adhesion sites, providing a sustained signalling response in collaboration with

GFRs such as ErbB2 to allow MEC proliferation.

B) ErbB2 can induce proliferation of MECs in an integrin-independent manner by activating the Rac1-Pak axis. 


\section{Additional Files}

Figure S1. GFP- $\beta 1$-integrin is incorporated to adhesion sites. MECs were transfected with the rescue vector containing the GFP- $\beta 1$-integrin and sh $\beta 1$-itg. Cells were cultured for three days before being trypsinised and replated onto glass coverslips. Cells were left to reattach for 24 hours prior to fixation and immunostaining. MECs were stained with antibodies to detect paxillin, GFP and active $\beta 1$-integrin_(clone 12G10). Immunofluorescence pictures of two transfected cells are shown. Colocalisation pictures of GFP- $\beta 1$-integrin and paxillin or GFP- $\beta 1$-integrin and active $\beta 1$-integrin are shown below. The colocalisation pictures were generated using ImageJ. Scale: $\underline{10} \mu \mathrm{m}$.

Figure S2. Rac1 activity is decreased in primary MECs treated with EHT1864. Primary cells grown on laminin-rich basement membrane were treaded with 0,10 or $20 \mathrm{nM}$ of EHT1864 for 48 hours. Cells were lysed and a Rac1 activity assay was performed on the lysates using GLisa Rac1 activity assay (Cytoskeleton, Cat. \# BK128). Error bars represent standard deviation of the mean from two readings $(n=1)$. 

A)

\begin{tabular}{|l|l|l|l|l|l|l|l|}
\hline EF1 $\alpha$ & CPPT & GFP & WPRE & LTR & tetO & H1 & sh $\beta 1$ \\
\hline
\end{tabular}

sh $\beta 1$ target region
\begin{tabular}{|l|l|c|c|c||c|c|c|c|c|}
\hline Ubiquitin & cPPT & $\beta 1$ & GFP & $\beta 1$-integrin & WPRE & LTR & tetO & H1 & sh $\beta 1$ \\
\hline
\end{tabular}

B)

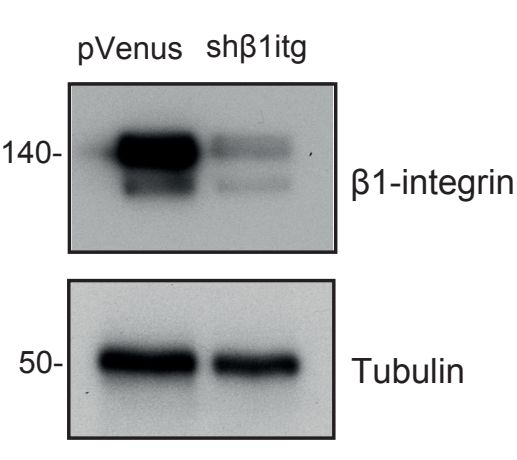

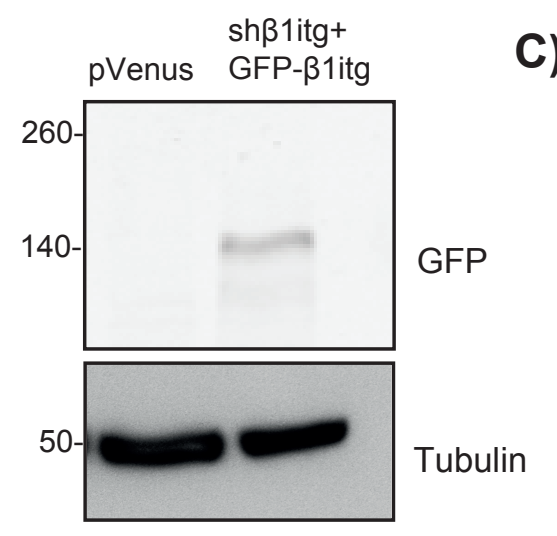

C)

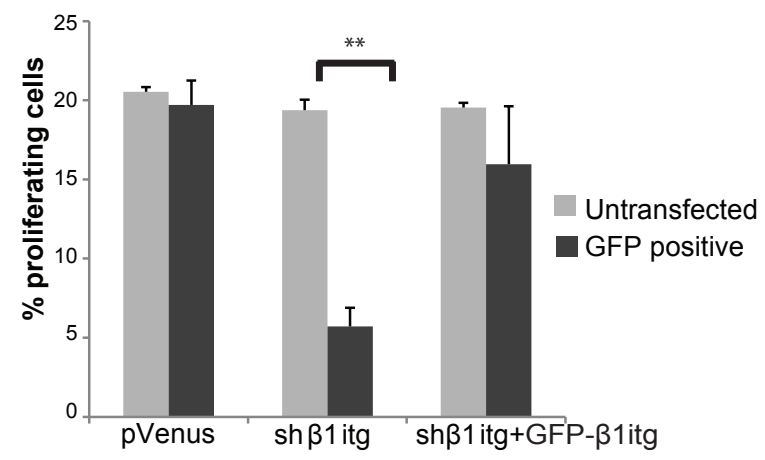

D)
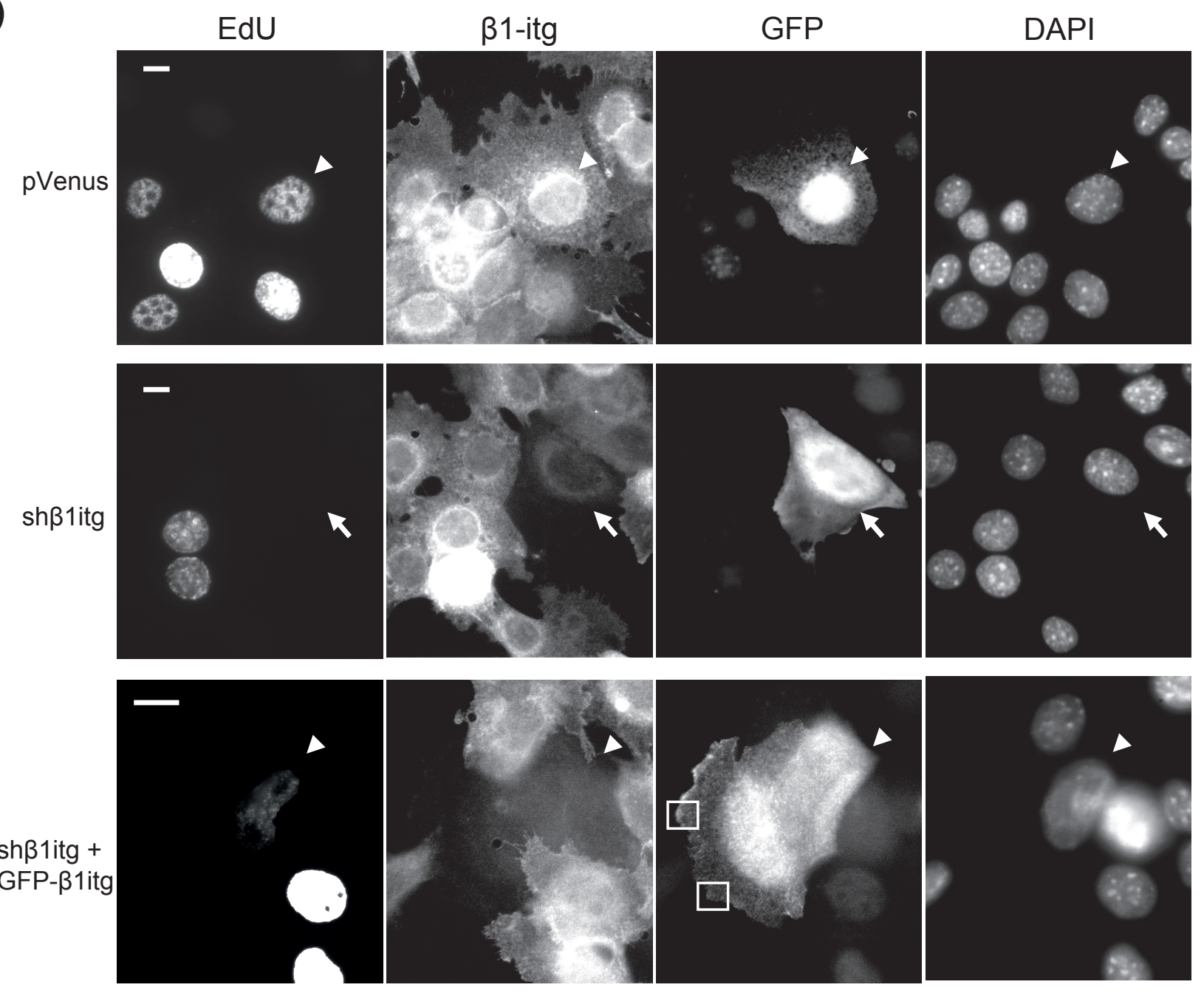

$\operatorname{sh} \beta 1$ itg + GFP- $\beta 1$ itg
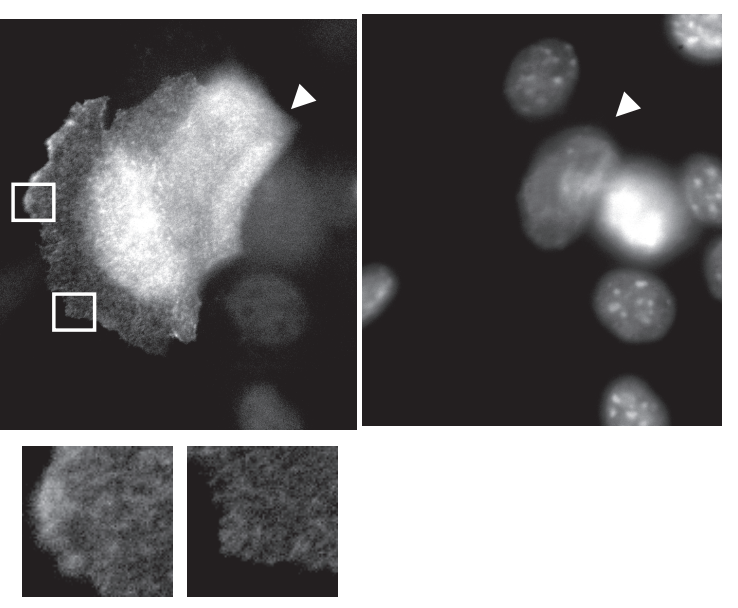
A)

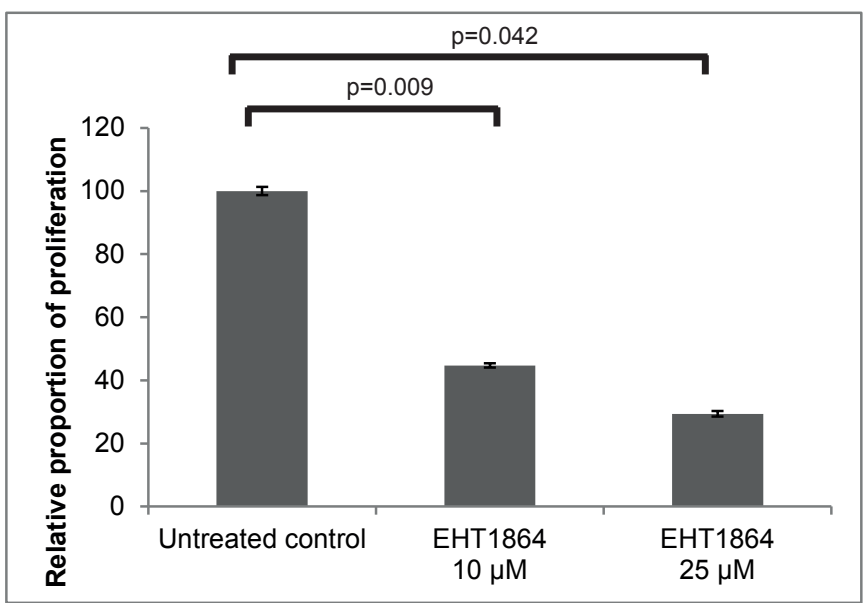

B) Rac1 + shß1-itg

\begin{tabular}{|l|l|l|l|l|l|l|l|l|}
\hline EF1a & cPPT & GFP & Rac1 & WPRE & LTR & tetO & H1 & sh $\beta 1$ \\
\hline
\end{tabular}

C)
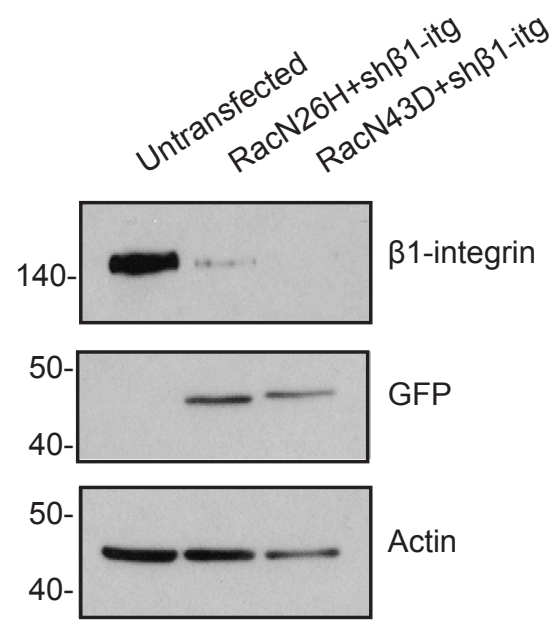

D)

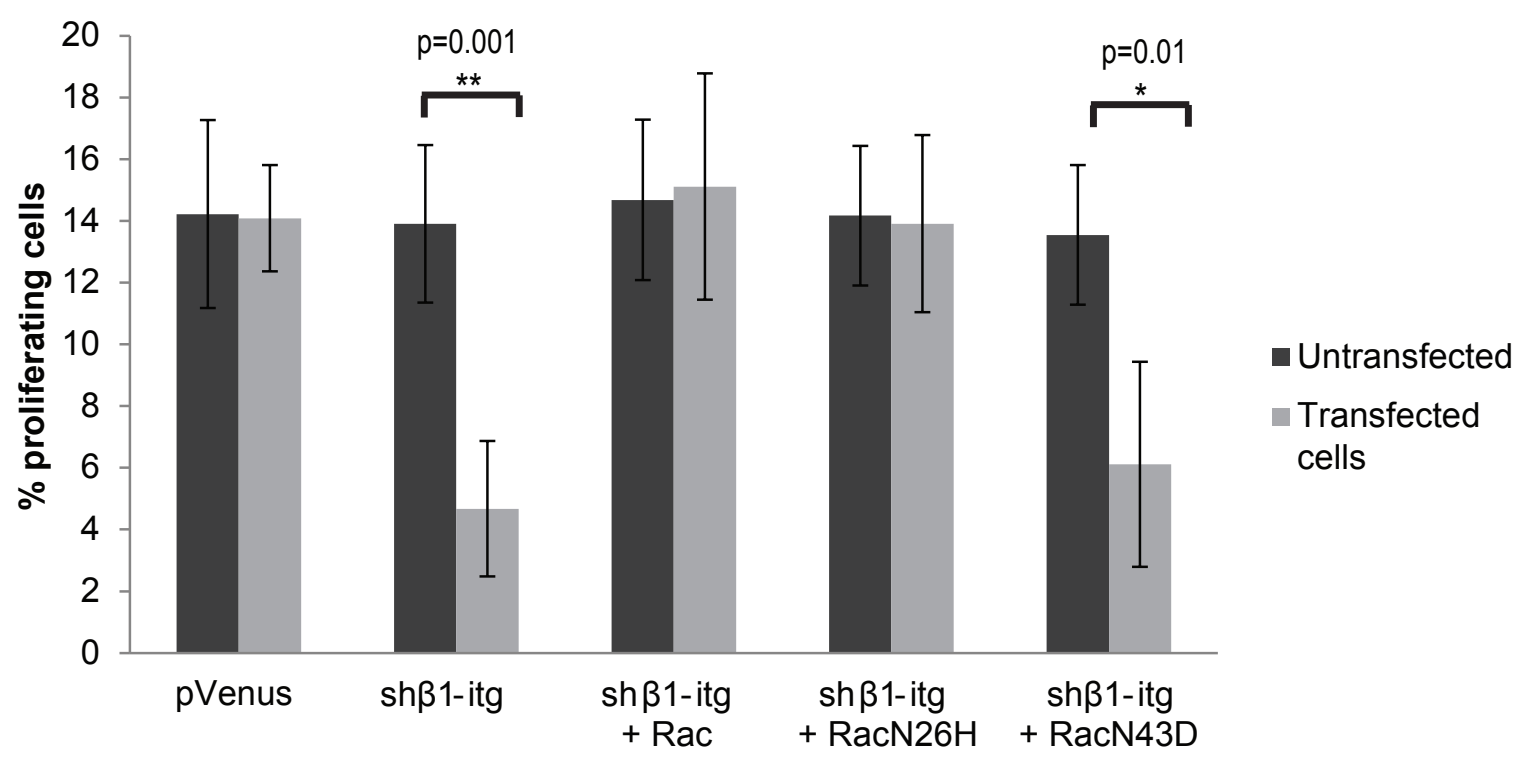

E)

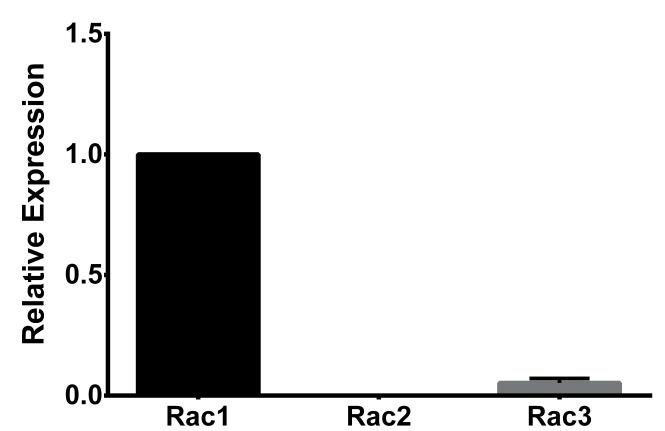


A)

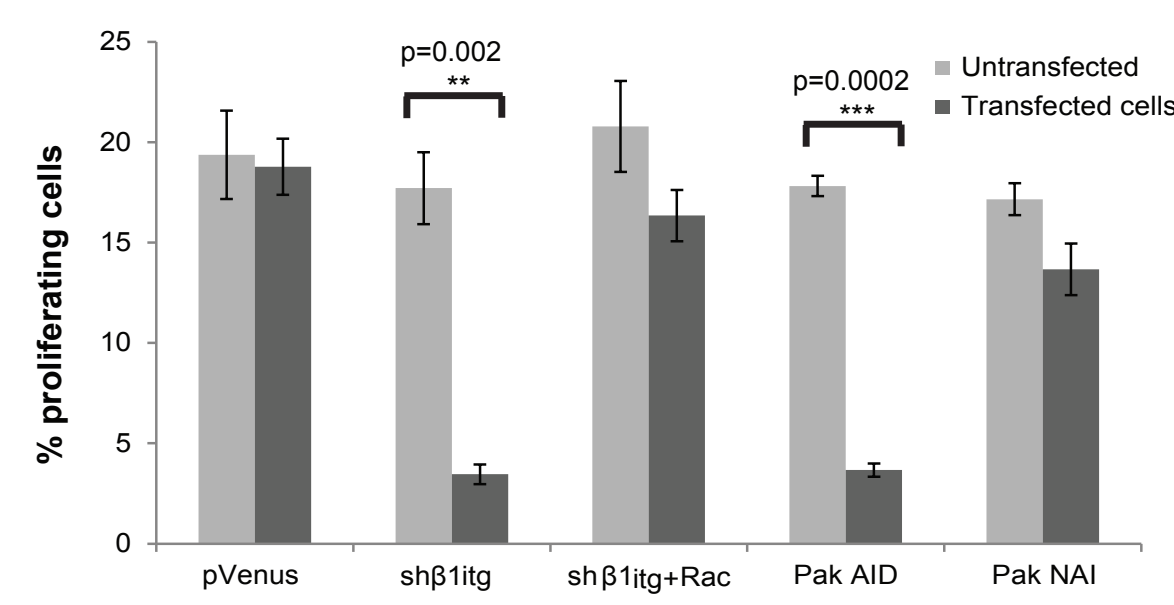

B)

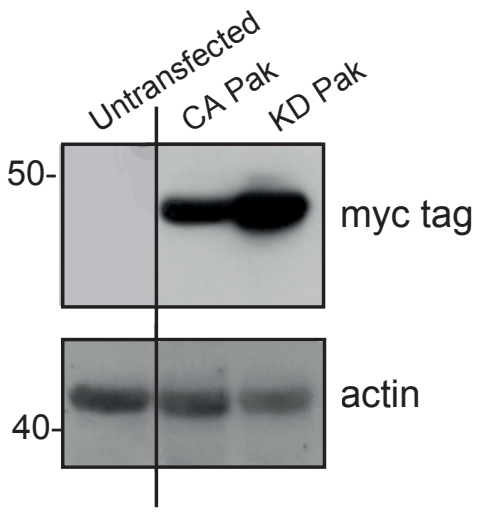

C)

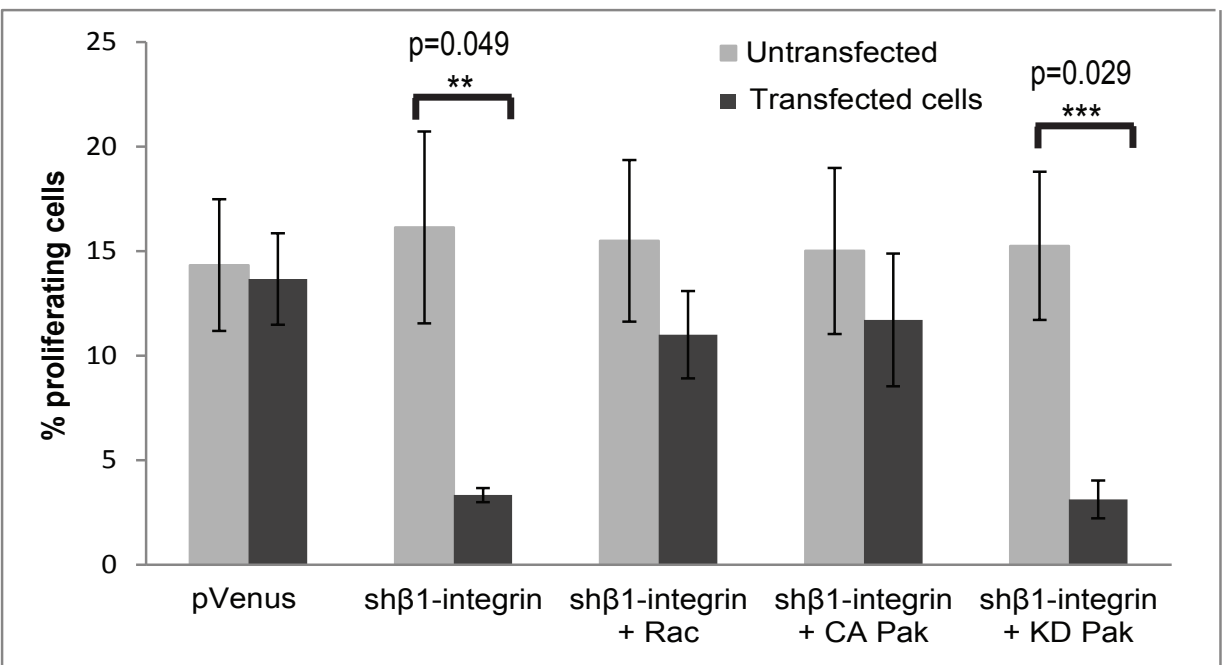

D)
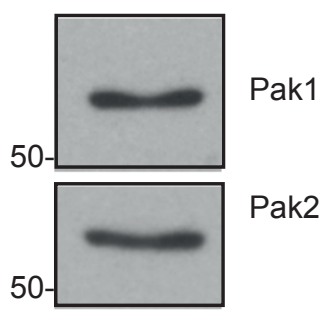

$40-$

Actin 
A) \begin{tabular}{|l|l|l|l|l|}
\hline EF1 $\alpha$ & v-ErbB2-V5 & 2A & GFP & WPRE v-ErbB2-V5 \\
\hline
\end{tabular}

\begin{tabular}{|l|l|l|l|l|l|l|l|l|l|} 
EF1 $\alpha$ & cPPT & v-ErbB2-V5 & 2A & GFP & WPRE & LTR & tetO & H1 & sh $\beta 1$ \\
v-ErbB2-V5-sh $\beta 1$
\end{tabular}

B)

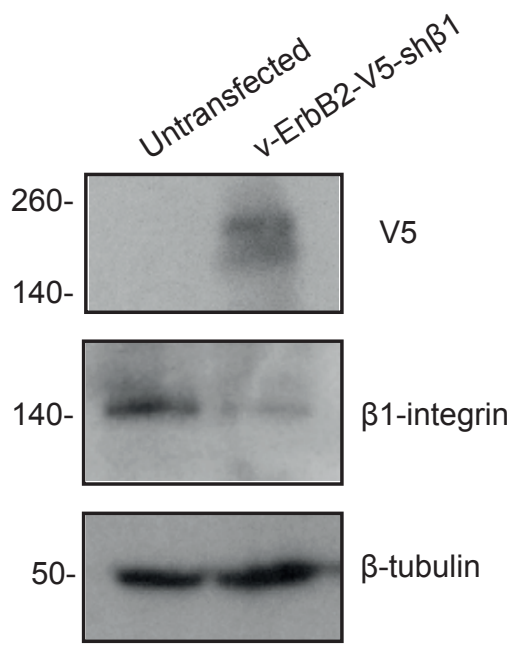

C)

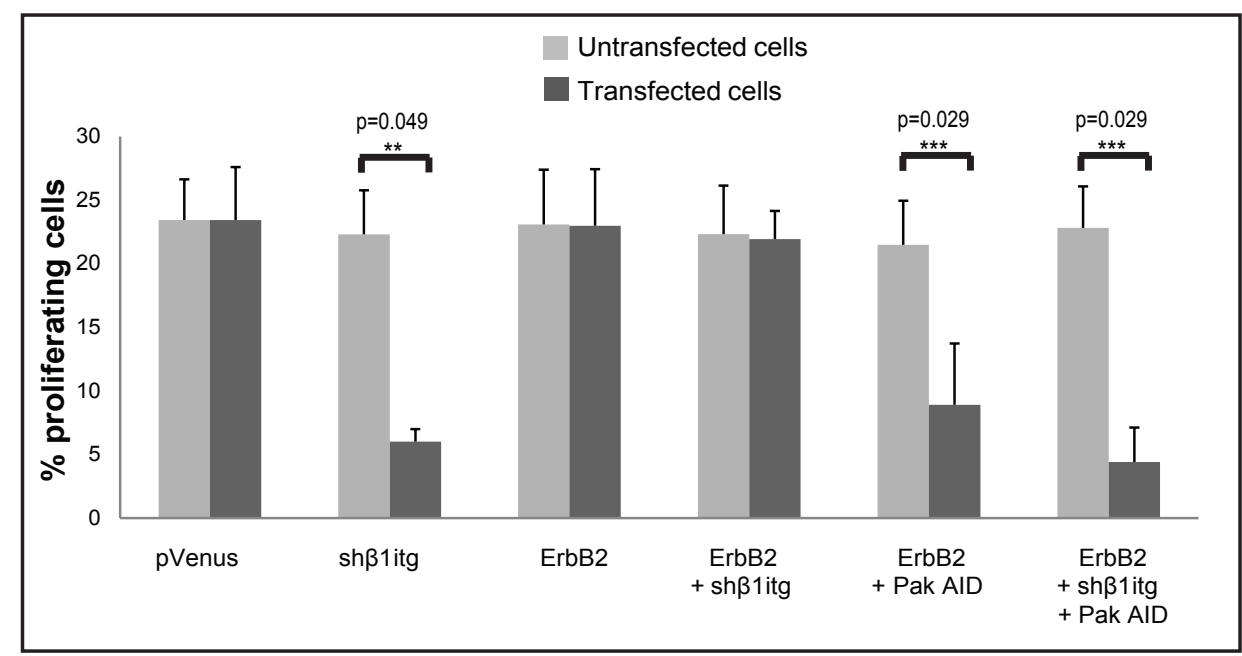

Fig 4 
A)

\begin{tabular}{|c|c|c|c|c|}
\hline EF1 1 & myrAkt & 2A & GFP & WPRE \\
\hline
\end{tabular}

B)
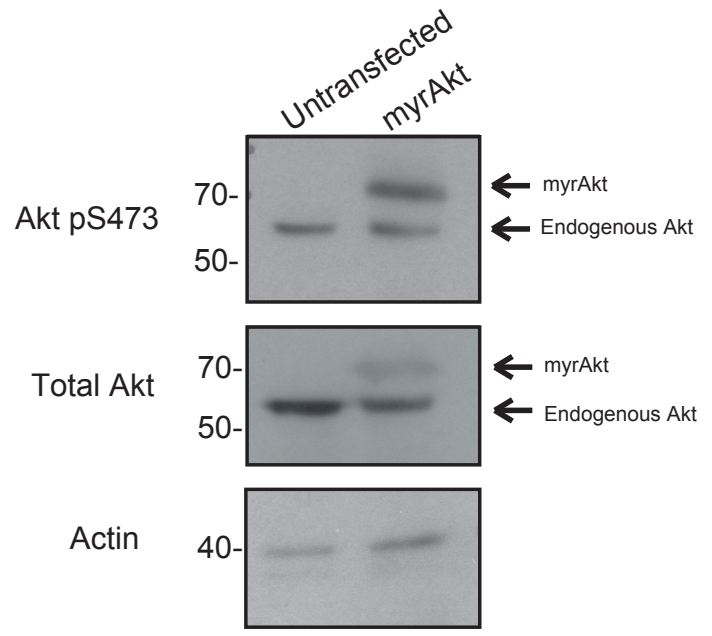

C)
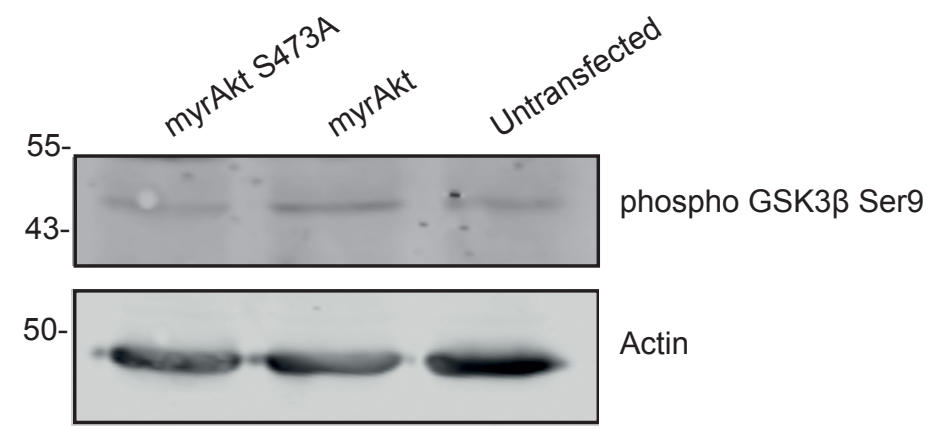

D)

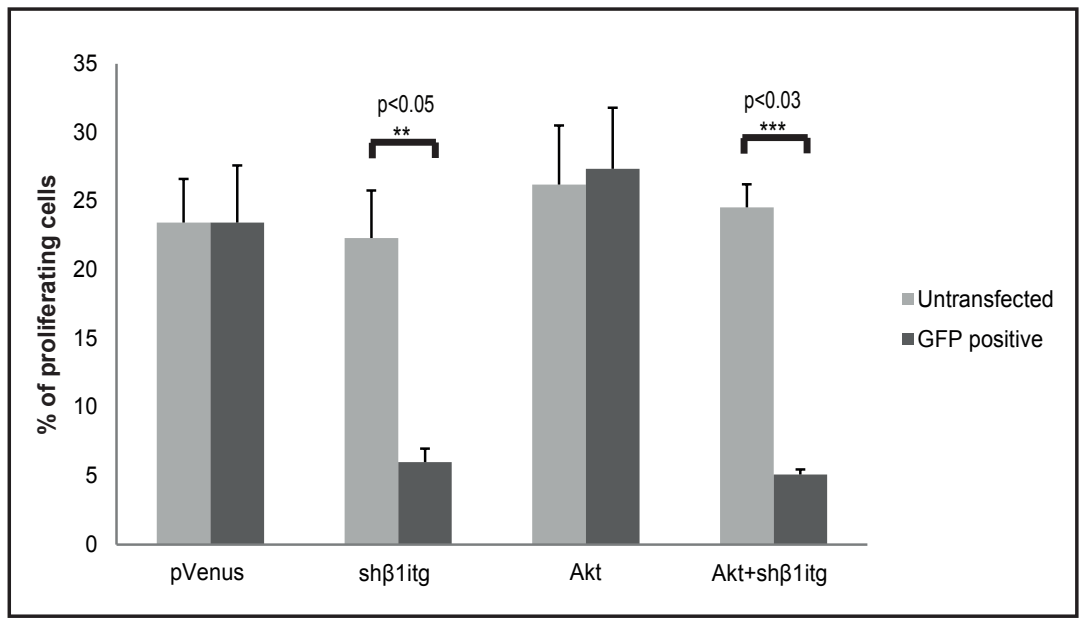

Fig 5 


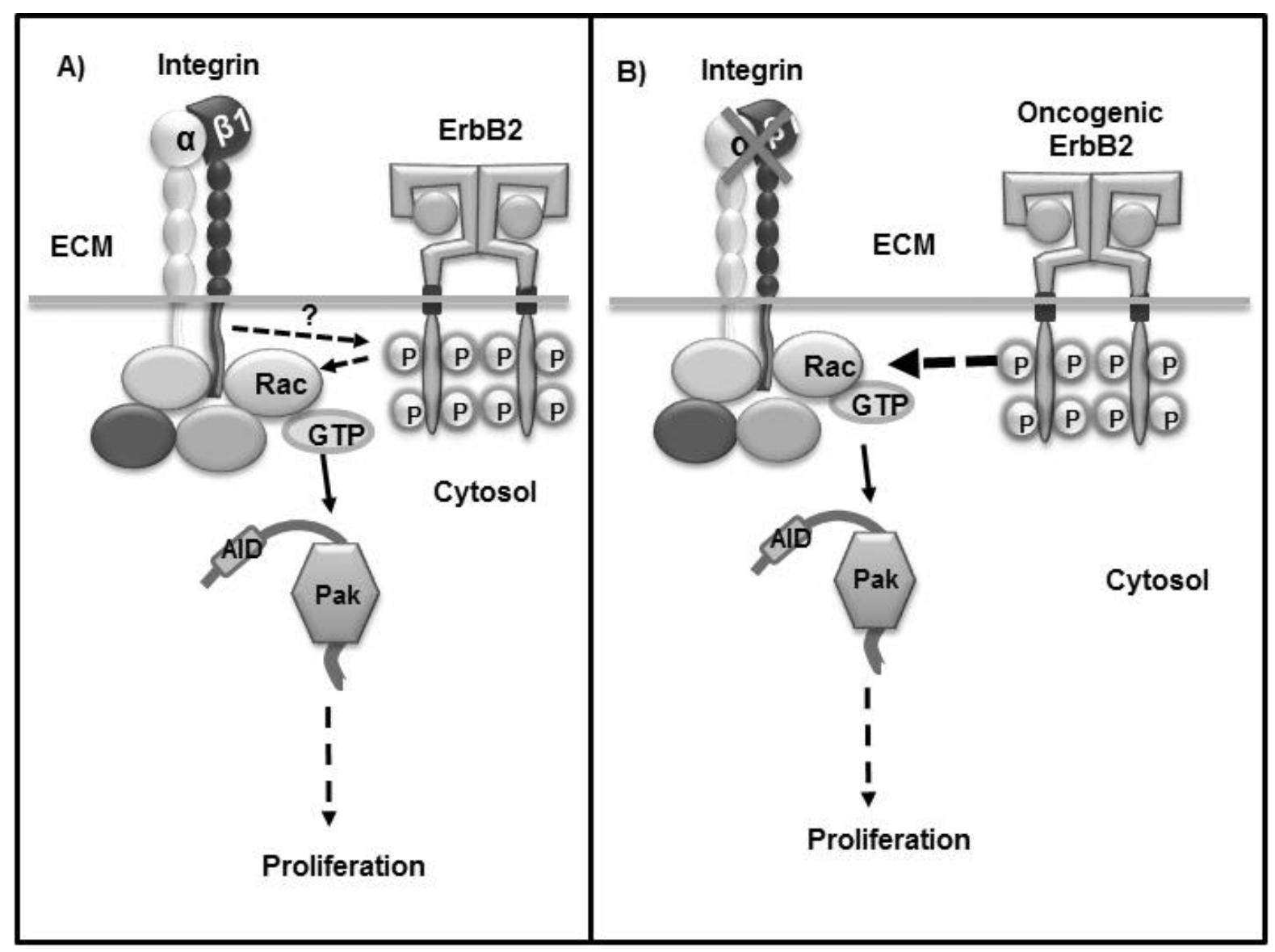

Fig 6 
Paxillin

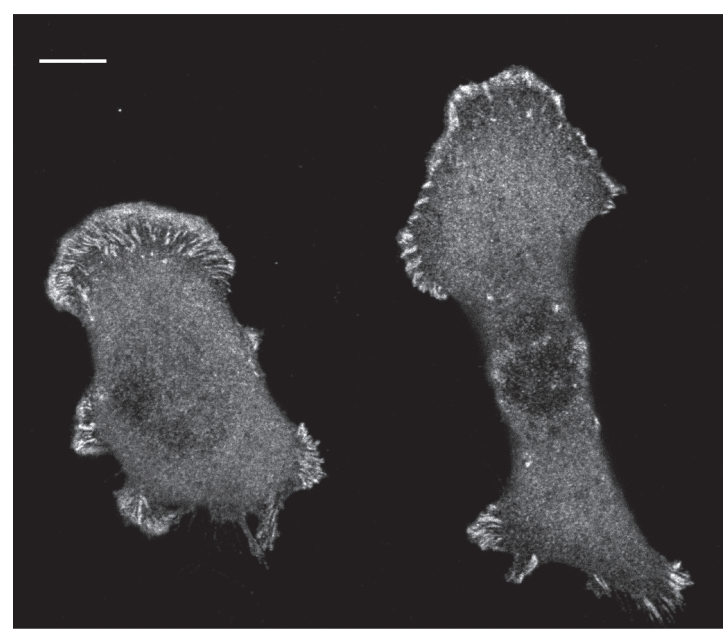

Colocalisation

Paxillin \& GFP- $\beta 1$ integrin

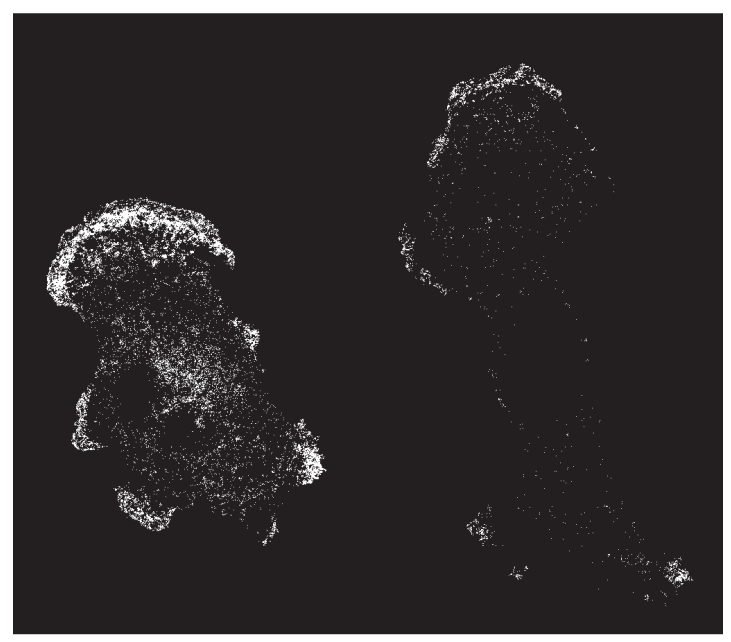

Active $\beta 1$ integrin
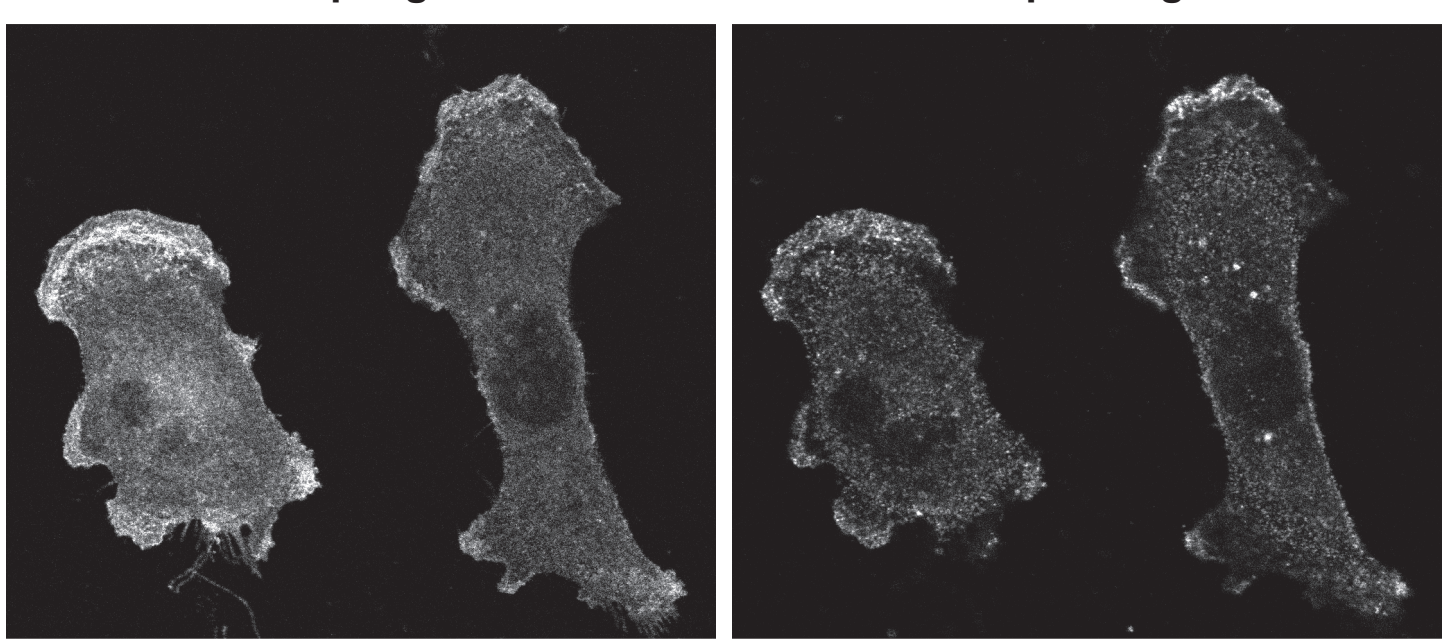

Colocalisation

GFP- $\beta 1$ itg \& Active $\beta 1$ integrin

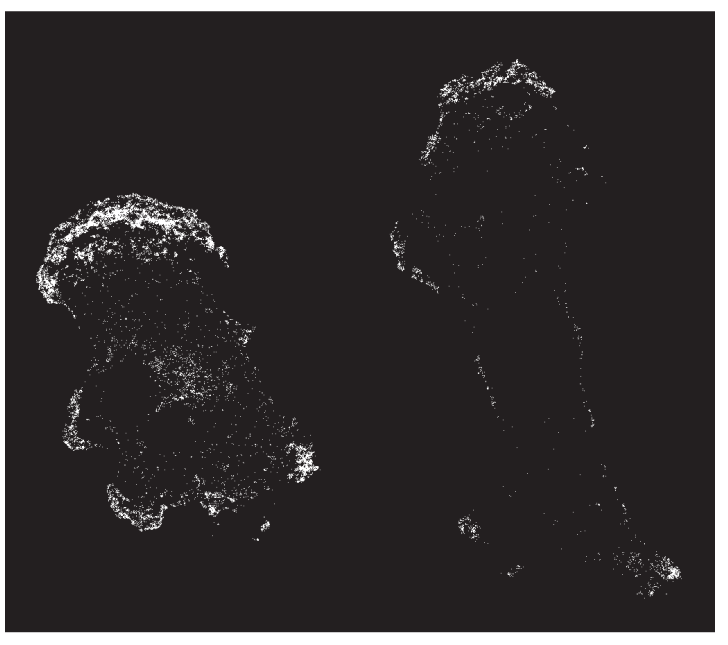

DAPI

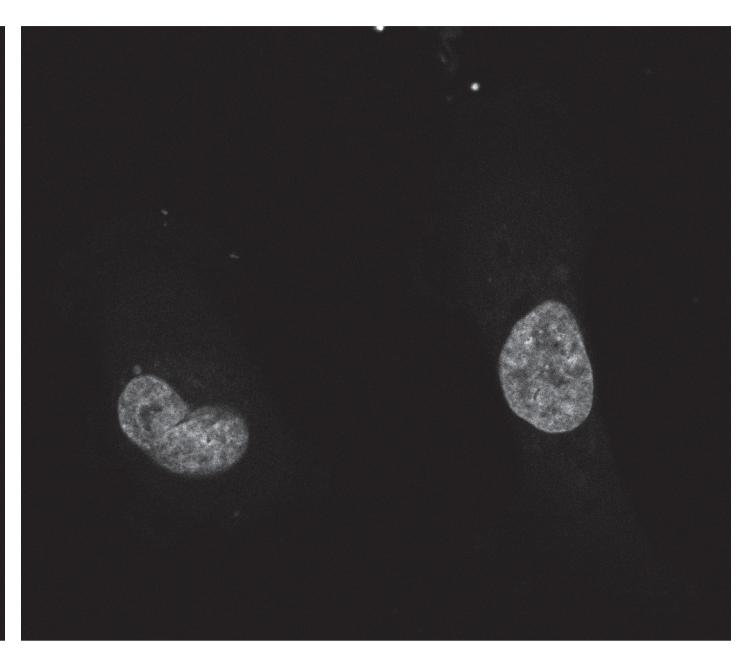




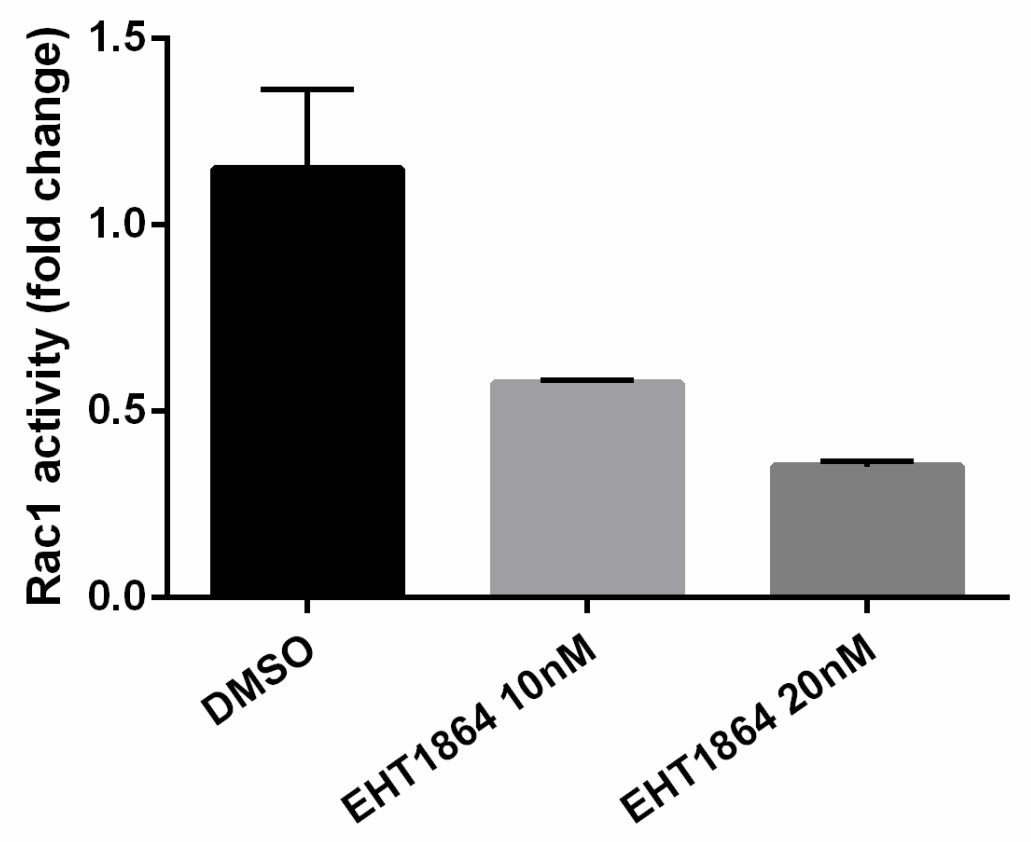

Fig S2 